\title{
Validated Heat-Transfer and Pressure-Drop
} Prediction Methods Based on the Discrete Element Method: Phase I, Three-Dimensional Roughness

Energy Systems Division Argonne National Laboratory 


\section{Argonne National Laboratory}

Argonne National Laboraton, with facilities in the states of Illinois and Idaho, is owned by the United States govemment, and operated by the University of Chicago under the provisions of a contract with the Department of Energy.

This technical memo is a product of Argonne's Energy Systems (ES)

Division. For information on the division's scientific and engineering activities, contact:

Director, Energy Systems Division

Argonne National Laboratory

Argonne, Illinois $60439-4815$

Telephone (708) 252-3724

Presented in this technical memo are preliminary results of ongoing work or work that is more limited in scope and depth than that described in formal reports issued by the ES Division.

\section{Disclaimer}

This report was prepared as an account of work sponsored by an agency of the United States Govemment. Neither the United States Government nor any agency thereof, nor any of their employees, makes any warranty, express or implied, or assumes any legal liability or responsibility for the accuracy, completeness, or usefulness of any information, apparatus, product, or process disclosed, or represents that its use would not infinge privately owned rights. Reference herein to any specific commercial product, process, or service by trade name, trademark, manufacturer, or otherwise, does not necessarily constitute or imply its endorsement, recomrnendation, or favoring by the United States Govemment or any agency thereof. The views and opinions of authors expressed herein do not necessarily state or reflect those of the United States Govemment or any agency thereof.

Reproduced directly from the best available copy.

Available to DOE and DOE contractors from the Office of Scientific and Technical Information, P.O. Box 62, Oak Ridge, TN 37831; prices available from (615) 576-8401.

Available io the public from the National Technical Information Service, U.S. Dspartment of Commerce, 5285 Port Royal Road, Springfield, VA 22161. 


\section{Validated Heat-Transfer and Pressure-Drop Prediction Methods Based on the Discrete Element Method: Phase I, Three-Dimensional Roughness}

by R.P. Taylor* and B.K. Hodge*

Energy Systems Division, Argonne National Laboratory, 9700 South Cass Avenue, Argonne, Illinois 60439

February 1992

Work sponsored by United States Department of Energy, Assistant Secretary for Conservation and Renewable Energy, Office of Renewable Energy Conversion

-Taylor and Hodge are affiliated with the Mechanical and Nuclear Engineering Department, Mississippi State University. 


\section{DISCLAIMER}

This document was prepared by R.P. Taylor and B.K. Hodge, Mechanical and Nuclear Engineering Department, Mississippi State University (Mississippi State, Miss.), for Argonne National Laboratory under contract 12952402. With the exception of minor modifications made to satisfy format requirements, the document is reproduced here as received. 


\section{CONTENTS}

LIST OF TABLES $\ldots \ldots \ldots \ldots \ldots \ldots \ldots \ldots \ldots \ldots \ldots \ldots \ldots$

LIST OF FIGURES $\ldots \ldots \ldots \ldots \ldots \ldots \ldots \ldots \ldots \ldots \ldots$

ACKNOWLEDGMENTS $\ldots \ldots \ldots \ldots \ldots \ldots \ldots \ldots \ldots \ldots \ldots$

NOMENCLATURE $\ldots \ldots \ldots \ldots \ldots \ldots \ldots \ldots \ldots \ldots \ldots \ldots$

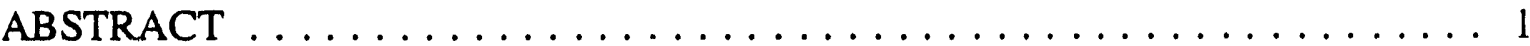

SECTION I INTRODUCTION $\ldots \ldots \ldots \ldots \ldots \ldots \ldots \ldots \ldots \ldots \ldots$

SECTION II FORMULATION OF THE DISCRETE ELEMENT

EQUATIONS FOR FULLY DEVELOPED FLOW IN A PIPE . . . . 4

2.1 Formulation of the Momentum Equation . . . . . . . . . 4

2.2 Formulation of the Energy Equation . . . . . . . . . . 6

2.3 Discussion of Thermally-Developed Flow . . . . . . . . . . 7

2.4 Constant Wall Heat Flux ................ . 12

2.5 Constant Wall Temperature ............... 13

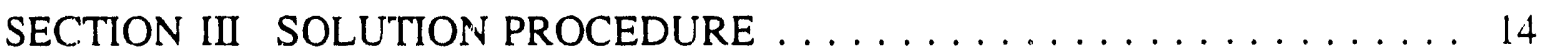

3.1 Momentum Equation Solution . . . . . . . . . . . . . 14

3.2 Energy Equation--Constant Wall Heat Flux . . . . . . . . . 16

3.3 Energy Equation--Constant Wall Temperature ......... 18

SECTION IV COMPARISON OF COMPUTATIONS AND EXPERIMENTS . . 19

$4.1 \quad$ Smooth Wall ........................ 19

$4.2 \quad$ Scaggs et al. ...................... 20

4.3 Dipprey and Sabersky ................ 20

4.4 Takahashi et al. . . . . . . . . . . . . . . . . . . . 29

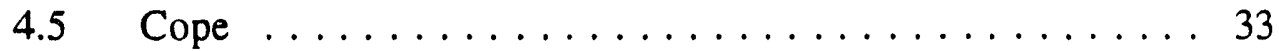

4.6 Gowen and Smith $\ldots \ldots \ldots \ldots \ldots \ldots$

4.7 Omitted Test Cases $\ldots \ldots \ldots \ldots \ldots \ldots \ldots \ldots \ldots$

SECTION V SUMMARY AND RECOMMENDATIONS . . . . . . . . . . 46

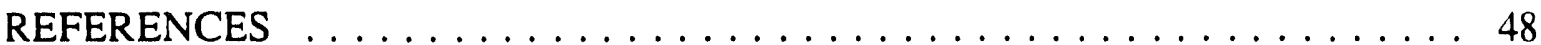


APPENDIX I THE IMPLICIT FINITE DIFFERENCE METHOD $\ldots \ldots \ldots \ldots 51$ APPENDLX II THE COMPUTER CODES $\ldots \ldots \ldots \ldots \ldots \ldots \ldots \ldots \ldots$ 


\section{LIST OF TABLES}

Page

Table 1 Laminar flow comparisons. . . . . . . . . . . . . 19

Table 2 Geometries of the roughness of Scaggs et al. ..........22

Table 3 Geometries for the cone model for Dipprey and

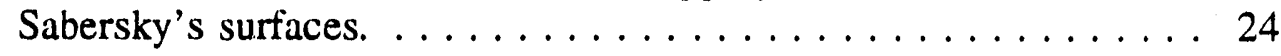

Table 4 Geometries for the cone model for Takahashi et al.'s surfaces. ....................... 33

Table $5 \quad$ Geometries for the cone model of Cope's surfaces. . . . . . . 37

Table 6 Dimensions for the spherical segment surfaces of Gowen and Smith. . .................. 41 


\section{LIST OF FIGURES}

Page

Fig. 1 Control volume diagram for fully developed pipe flow. $\ldots \ldots \ldots 5$

Fig. 2 Schematic diagram illustrating the idea of thermally developed flow. ...................... 9

Fig. 3 Comparison of smooth-wall computations of friction factor and Nusselt number with accepted correlations and the data

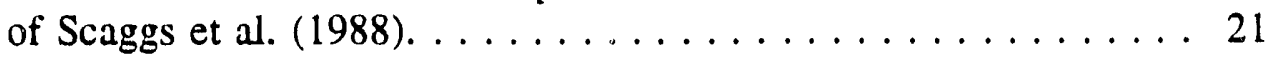

Fig. 4 Surface roughness geometry for the experiments of

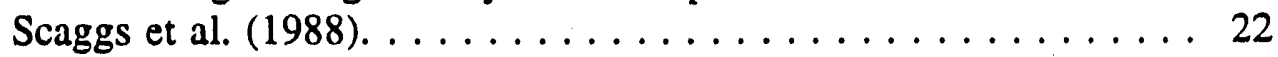

Fig. 5 Comparison of discrete element computations with the large hemisphere roughness data of Scaggs et al. (1988). . . . . . . 23

Fig. 6 Comparison of discrete element computations with the cone roughness of Scaggs et al. (1988). . . . . . . . . . . . . . . 24

Fig. 7 Comparison of discrete element computations with the small hemisphere roughness of Scaggs et al. (1988). . . . . . . . 25

Fig. 8 Comparison of the discrete element computations with the data for tube D-3 of Dipprey and Sabersky $(1963) \ldots \ldots \ldots \ldots 26$

Fig. 9 Comparison of the discrete element computations with the data for tube C-9 of Dipprey and Sabersky (1963). . . . . . . . 27

Fig. 10 Comparison of the discrete element computations with the data for tube A-4 of Dipprey and Sabersky (1963). . . . . . . . . 28

Fig. 11 Roughness element geometry for tube A-3 from Takahashi et al. (1985), all dimensions in mm. ......... 30

Fig. 12 Roughness element geometry for tube A-6 from Takahashi et al. (1985), all dimensions in mm. ......... 31

Fig. 13 Roughness element geometry for tube A-8 from Takahashi et al. (1985), all dimensions in $\mathrm{mm}$. 
Fig. 14 Comparison of discre.e element computations with the data for tube A-3 of Takahashi et al. (1985). . . . . . . . . . . . . 34

Fig. 15 Comparison of discrete element computations with the data for tube A-6 of Takahashi et al. (1985). . . . . . . . . . . . . 35

Fig. 16 Comparison of discrete element computations with the data for

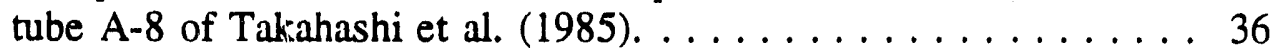

Fig. 17 Co.nparison of discrete element computations with the data for

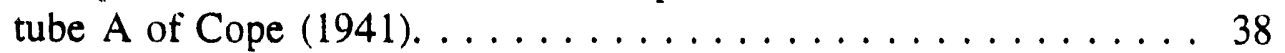

Fig. 18 Comparison of discrete element computations with the data for tube B of Cope (1941). . . . . . . . . . . . . . . . . 39

Fig. 19 Comparison of discrete element computations with the data for tube C of Cope (1941). . . . . . . . . . . . . . . . . 40

Fig. 20 Diagram illustrating the manufacture of roughness by

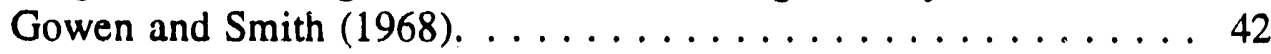

Fig. 21 Comparison of discrete element compurations with the cata for tube R-2 of Gowen and Smith (1968). . . . . . . . . . . . 43

Fig. 22 Comparison of discrete element computations with the data for tube R-3 of Gowen and Smith (1968). . . . . . . . . . . 44

Fig. I-1 Layout of the es panding finite difference grid. $\ldots \ldots \ldots 52$

Fig. I-2 Matrix from linearized equations: a) tridiagonal form;

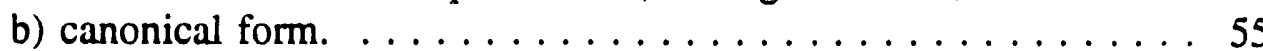




\section{ACKNOWLEDGMENTS}

This work was supported under Contract 12952402 from Argonne National Laboratory. We gratefully acknowledge the support and encouragement of Mr. Tom Rabas of Argonne. 
NOMENCLATURE

\begin{tabular}{|c|c|}
\hline $\begin{array}{l}A_{n} \\
A_{p}\end{array}$ & $\begin{array}{l}\text { coefficient in the finite difference equations } \\
\text { projected frontal area }\end{array}$ \\
\hline$A_{s}^{p}$ & surface area \\
\hline$A_{x}$ & area normal to $\mathrm{x}$-axis \\
\hline$A_{y}$ & area normal to $y$-axis \\
\hline$B_{n}$ & coefficient in the finite difference equations \\
\hline$C_{D}$ & local element drag coefficient \\
\hline $\mathrm{C}_{\mathrm{n}}$ & coefficient in the finite difference equations \\
\hline$c_{p}$ & specific heat \\
\hline d & local element diameter \\
\hline $\begin{array}{l}d_{0} \\
D\end{array}$ & $\begin{array}{l}\text { element base diameter } \\
\text { pipe diameter }\end{array}$ \\
\hline$D_{n}$ & $\begin{array}{l}\text { pipe diameter } \\
\text { coefficient in the finite difference equations }\end{array}$ \\
\hline$E_{n}$ & coefficient in the canonical equations \\
\hline$f_{f}$ & Fanning friction factor \\
\hline$\vec{F}_{D}$ & drag force on the control volume \\
\hline$\overline{\mathrm{h}}$ & local convective heat transfer coefficient \\
\hline k & element height \\
\hline k' & projected height for truncated cone \\
\hline $\mathrm{k}_{\mathrm{s}}$ & equivalent sand-grain roughness scale \\
\hline $\mathrm{K}$ & thermal conductivity \\
\hline $\mathrm{K}_{\mathrm{T}}$ & turbulent thermal conductivity \\
\hline$\ell$ & element spacing (Figure 1) \\
\hline$l_{\mathrm{m}}$ & mixing length \\
\hline $\mathrm{L}$ & element spacing (Figure 1) \\
\hline $\mathrm{L}^{*}$ & eddy viscosity parameter \\
\hline $\mathrm{L}^{* *}$ & eddy conductivity parameter \\
\hline$\dot{\mathbf{m}}$ & mass flow rate \\
\hline $\mathbf{N}$ & number of points in the grid \\
\hline $\begin{array}{l}\mathrm{N}_{\text {elem }} \\
\mathrm{Nu}\end{array}$ & $\begin{array}{l}\text { number of elements in the control volume } \\
\text { pipe Nusselt number }\end{array}$ \\
\hline $\mathrm{Nu}_{\mathrm{d}}$ & local element Nusselt number \\
\hline $\mathrm{Nu}_{\mathrm{H}}$ & value for constant wall heat flux problem \\
\hline $\mathrm{Nu}_{\mathrm{T}}$ & value for constant wall temperature problem \\
\hline$P$ & pressure \\
\hline $\operatorname{Pr}$ & Prandtl number \\
\hline $\operatorname{Pr}_{T}$ & turbulent Prandtl number \\
\hline$\dot{q}^{T}$ & heat flux \\
\hline Q & heat rate added to control volume by roughness elemen \\
\hline $\mathrm{r}$ & radius \\
\hline $\mathbf{R}$ & pipe radius; also, grid step size ratio \\
\hline
\end{tabular}




$\begin{array}{ll}\operatorname{Re}_{\mathrm{d}} & \text { local element Reynolds number } \\ \mathrm{Re}_{\mathrm{D}} & \text { pipe Reynolds number } \\ \mathrm{T} & \text { temperature } \\ \mathrm{T}_{\mathrm{c}} & \text { center-line temperature } \\ \mathrm{T}_{\mathrm{O}} & \text { wall temperature } \\ \mathrm{T}_{\mathrm{R}} & \text { roughness element temperature }\left(\text { Taken }=\mathrm{T}_{\mathrm{o}} \text { ) }\right. \\ \mathrm{u} & \text { velocity profile } \\ \mathrm{U}_{\mathrm{m}} & \text { mean velocity } \\ \mathrm{w} & \text { solution variable in finite difference equation } \\ \mathrm{x} & \text { streamwise coordinate } \\ \mathrm{y} & \text { coordinate normal to wall }(=1-\mathrm{r}) \\ \mathrm{Y} & \text { fixed value of } \mathrm{y}\end{array}$

\section{Greek}

$\begin{array}{ll}\alpha & \text { thermal diffusivity } \\ \beta_{\mathrm{x}} & \text { x-area blockage } \\ \beta_{\mathrm{y}} & \text { y-area blockage } \\ \gamma & \text { coefficient of linearized differential equation } \\ \Delta & \text { y-length scale } \\ \delta_{\mathrm{x}} & \text { x-length of control volume } \\ \delta_{\mathrm{y}} & \text { y-length of control volume } \\ \Delta \mathrm{T} & \text { temperature scale } \\ \eta & \text { coordinate in tinite difference solution } \\ \theta & \text { nondimensional temperature } \\ \theta^{*} & \text { iterative guess of } \theta \\ \lambda_{\mathrm{n}} & \text { coefficient in the canonical equations } \\ \mu & \text { viscosity } \\ \mu_{\mathrm{T}} & \text { turbulent eddy viscosity } \\ \rho & \text { density } \\ \tau & \text { shear momentum flux }\end{array}$

\section{Superscripts}

indicates nondimensionalization $=/ / \mathrm{R}$, except $\tilde{u}=u / U_{m}, \tilde{\theta}=\theta / N u$.

$\underline{\text { Subscripts }}$

m

indicates a mean value 


\title{
VALIDATED HEAT-TRANSFER AND PRESSURE- DROP PREDICTION METHODS BASED ON THE DISCRETE ELEMENT METHOD: \\ Phase I, Three-Dimensional Roughness
}

by

\author{
R.P. Taylor and B.K. Hodge
}

\begin{abstract}
A computer program based on the discrete element method has been developed and validated to compute friction factors and Nusselt numbers for fully developed turbulent flow and heat transfer in pipes with three-dimensional roughness elernents. Computational results are compared with appropriate cases from heat transfer experiments in the literature. The predictions were in general in very good agreement with the experimental data.
\end{abstract}

\section{SECTION I}

\section{INTRODUCTION}

Heat transfer enhancement using three-dimensional roughriess elements is attractive because of the energy efficiency and level of augmentation. The major liability is the high fouling propensity. For nonfouling applications three-dimensional roughness may be the preferred enhancement geometry. This report presents the results of a research project to formulate a prediction approach based on the discrete element method for the heat transfer and friction factor for the internal surface of a pipe roughened with three-dimensional roughness elements. Results of computations using this model are compared with existing experimental data from the literature.

The two basic categories in which rough-wall boundary layer calculation efforts have fallen are (1) the equivalent sandgrain approach and (2) the discrete element approach. While both methods require experimental input, the equivalent sandgrain approach may require experimental data on the particular surface under consideration. The discrete element approach incorporates more basic physics of the process and uses a more generalized, empirically based input. It is therefore applicable to a broader spectrum of rough surfaces without requiring surface-specific experimental data. 
The discrete element approach considers the mass, momentum and energy transport processes on the collection of individual roughness elements and the smooth surface between the elements. The basic idea is to formulate a system of partial differential equations that describes the mass, momentum and energy transport for the flow over, around and between the roughness elements. In this method, the roughness effects are takin as an integral part of the flow problem and not (as with the equivalent sindgrain approach) as some ill-defined boundary condition.

Schlichting (1936), in the same paper in which he introduced the equivalent sandgrain roughness concept, briefly discussed an alternative approach similar to the discrete element approach. He proposed that the flow resistance of a rough surface be divided into two componerits: i) that due to the form drag on the element, and 2) that due to the viscous shear on the smooth suriace area between the roughness elements.

In recent years, various attempts to use the discrete element approach as a basis for calculation methods have been presented (Finson, 1975, Adams and Hodge, 1977, Finson and $\mathrm{Wu}, 1979$, Finson and Clark, 1980, Lin and Bywater, 1980. Finson, 1982, Christoph, 1982, Christoph and Pletrher, 1983). The authors and their colleagues (Taylor, Coleman, and Hodge, 1984, 1985), following the basic idea of Schlichting and building on the preceding works listed above, dorived from first principles tile discrete element approach for two-dimensional boundary layer flow that included the physicial effects of roughness in the equations which govern the flow. This scheme includes the effects of roughness on the flowfield by considering the blockage effects of the roughness elements, the drag forces which the roughness elements exert on the flowfield, and the heat transfer between roughness elements and the flow. It does not rely on definition of an equivalent sandgrain roughness. Excellent agreement between the discrete element approach predictions and experimental results has been demonstrated for heat transfer and skin friction in aerodynamic turbulent boundary layers over surfaces roughened with three-dimensional elements (Hosni et al., 1989, 1991).

Previous work by the principal investigators and their colleagues (Scaggs et al., 1988a, Taylor et al., 1988, and Scaggs, et al., 1988b) showed excellent agreement between discrete element method predictions and experimental data for friction factors in fully developed turbulent pipe flow with three-dimensional roughness elements. However, the heat transfer prediction capability of the discrete element method has never been validated for fully developed flow and heat transfer in pipes. Such heat transfer predictions are important in enhanced heat transfer applications.

The general organization of the work presented in the following sections is described below. Section II contains the formulation of the discrete element method for fully developed flow in a pipe. Included in this section are derivations of the partial differential equations with the discrete element method and a discussion of the concept of thermally-developed flow for rough-wall pipes. Section III describes the 
solution procedure. Section IV discusses the validation cases from the literature and presents comparisons of results from computations using the present prediction method and experimental data from the validation cases. Section V provides a concluding discussion and recommendations for future work. Appendices I and II present the finite difference solution procedure and the FORTRAN subroutines that are used in the solution procedure. 


\section{SECTION II \\ FORMULATION OF THE DISCRETE ELEMENT \\ EQUATIONS FOR FULLY DEVELOPED FLOW IN A PIPE}

The roughness model used in this formulation is the discrete element method of Taylor et al. (1984). This scheme includes the physical effects of roughness on the flow by considering the blockage effects of the roughness elements, the drag forces that the roughness elements exert on the flow, and the heat transfer between the roughness elements and the flow. The equations are formulated by performing mass, momentum, and energy balances on a differential control volume as shown in Figure 1. This control volume is a cylindrical shell which is long enough to contain a significant sample of the roughness elements.

In the following, fully developed flow and heat transfer are assumed. Firthermore, the flow is assumed to be incompressible and to have constant fluid properties. The roughness is assumed to be a uniform array of elements with circular cross-section.

\subsection{Formulation of the Momentum Equation}

For fully-developed flow, the momentum balance becomes a balance between shear forces, pressure forces, and drag forces as shown in Figure 1. The balance is written as

$$
0=\left.\left(P A_{x}\right)\right|_{x}-\left.\left(P A_{x}\right)\right|_{x+\delta x}-F_{D}+\left.\left(\tau A_{y}\right)\right|_{y}-\left.\left(\tau A_{y}\right)\right|_{y+\delta y}
$$

The areas $A_{x}$ and $A_{y}$ are given by

$$
\begin{aligned}
& A_{x}=2 \pi r(\delta y) \beta_{x} \\
& A_{y}=2 \pi r(\delta x) \beta_{y}
\end{aligned}
$$

where the $\beta$ 's are the blockage factors which represent the area of the control surface that is open for flow. The drag force is expressed in terms of the local drag coefficient as

$$
F_{D}=\frac{1}{2} \rho C_{D} u^{2} A_{p} N_{\text {elem }}
$$



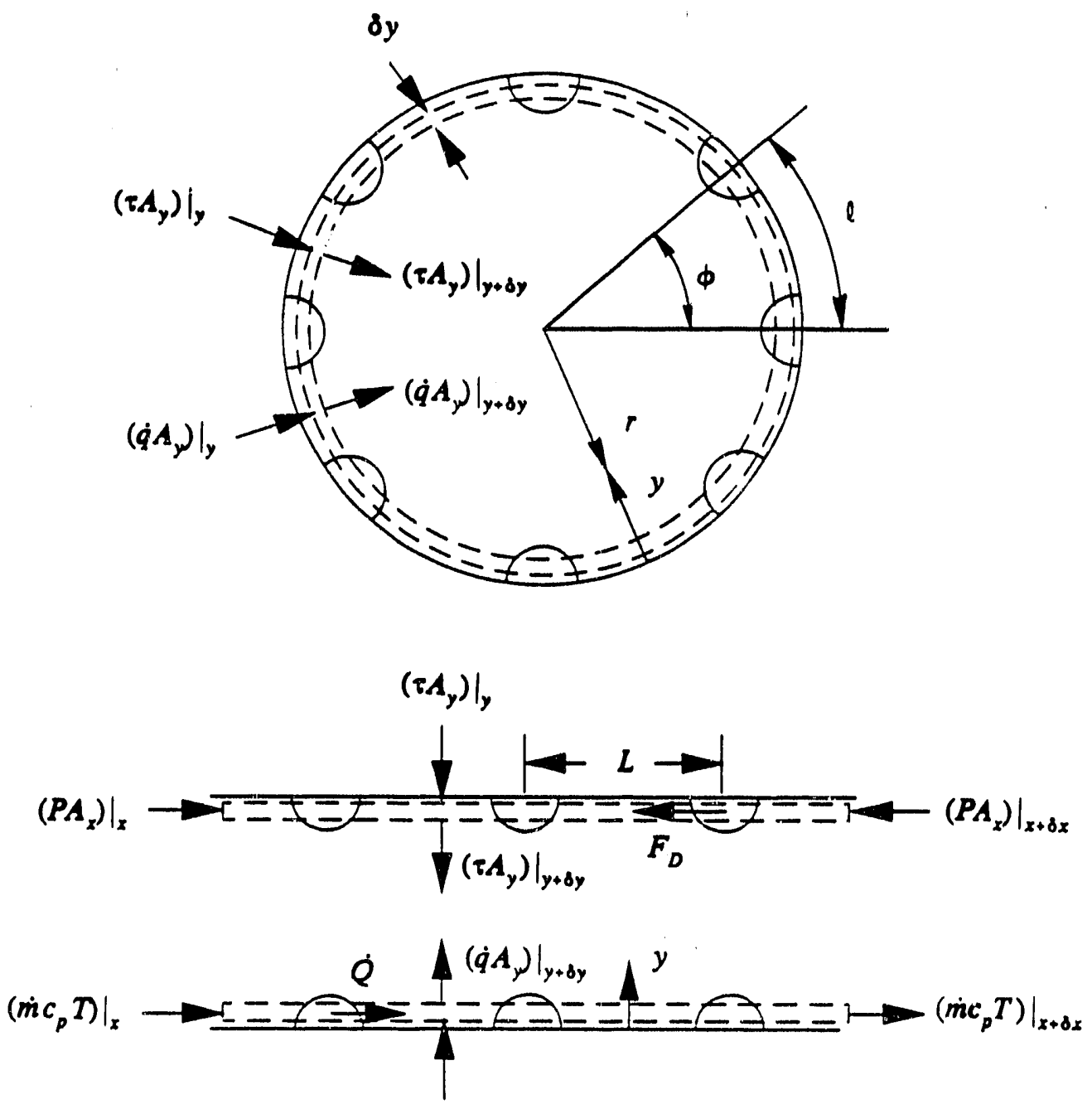

$$
\left.\left(\dot{q} A_{j}\right)\right|_{y}
$$

Fig. 1. Control volume diagram for fully developed pipe flow.

If the roughness elements are taken to have circular cross-sections, the projected area is $A_{p}=d(y) \delta y$ and the number of elements in the control volume is $N_{\text {elem }}=$ $(2 \pi R \delta x) /(\ell L)$. Substituting into the momentum balance, dividing through by $\delta x \delta y$, and taking the limit as $\delta_{x}, \delta_{y} \rightarrow 0$ gives

$$
0=-\frac{\partial}{\partial y}\left(\beta_{y} r \tau\right)-r \frac{\partial}{\partial x}\left(\beta_{x} P\right)-\frac{1}{2} \rho C_{D} u^{2} \frac{d(y) R}{\ell L}
$$


When the concept of eddy viscosity is used, the shear flux is expressed as

$$
\tau=-\mu\left(1+\frac{\mu_{T}}{\mu}\right) \frac{\partial u}{\partial y}
$$

For fully developed flow, the pressure gradient is constant. Furthermore, if it is assumed that $\partial \beta_{x} / \partial x=0$, the momentum balance is given by the following ordinary differential equation for constant property fiow.

$$
0=\frac{\mu}{r} \frac{d}{d y}\left[r \beta_{y}\left(1+\frac{\mu_{T}}{\mu}\right) \frac{\partial u}{\partial y}\right]-\beta_{x} \frac{d P}{d x}-\frac{1}{2} \rho C_{D} u^{2} \frac{d(y) R}{r \ell L}
$$

The boundary conditions are

$$
\begin{aligned}
& y=0, u=0 \\
& y=R, \quad \frac{d u}{d y}=0
\end{aligned}
$$

\subsection{Formulation of the Energy Equation}

Applying an energy balance to the control volume and neglecting changes in kinetic energy, shear work, and axial conduction gives

$$
0=\left.\left(\dot{m} c_{p} T\right)\right|_{x+\delta x}-\left.\left(\dot{m} c_{p} T\right)\right|_{x}+\left.\left(\dot{q} A_{y}\right)\right|_{y+\delta y}-\left.\left(\dot{q} A_{y}\right)\right|_{y}-\dot{Q}
$$

The local heat transfer rate between the elements and the fluid, $\dot{Q}$, is expressed in terms of the local element Nusselt number as

$$
\dot{Q}=\frac{K}{d(y)} N u_{d} A_{s} N_{\text {dlem }}\left(T_{R}-T\right)
$$

The local surface area for elements with circular cross sections is given by $A_{s}=\pi d(y) \delta y$. Substituting the expression for the number of elements and taking $\mathrm{T}_{\mathrm{R}}=\mathrm{T}_{\mathrm{o}}$ gives 


$$
\dot{Q}=K N u_{d} \pi \delta y \frac{2 \pi R \delta x}{\ell L}\left(T_{o}-T\right)
$$

Using $\dot{m}=\rho u A_{x}$, and equations (2) and (3) for $A_{x}$ and $A_{y}$, dividing through by $\delta x \delta y$, and taking the limit as $\delta x, \delta y \rightarrow 0$ gives

$$
0=\frac{\partial}{\partial x}\left(\rho u r \beta_{x} c_{p} T\right)+\frac{\partial}{\partial y}\left(r \beta_{y} \dot{q}\right)-K N u_{d} \pi \frac{R}{l L}\left(T_{o}-T\right)
$$
becomes

With the concept of eddy conductivity, Fourier's law expression for the heat flux

$$
\dot{q}=-K\left(1+\frac{\mathbb{X}_{T}^{\prime}}{K}\right) \frac{\partial T}{\partial y}
$$

For constant property fully-developed flow, $\partial\left(\rho u \beta_{x}\right) / \sigma_{i}:=0$ and with $\partial \beta_{x} / \partial x \approx 0$ conservation of energy appears as

$$
0=\rho c_{p} \beta_{x} u r \frac{\partial T}{\partial x}-K \frac{\partial}{\partial y}\left[r \beta_{y}\left(1+\frac{K_{T}}{K}\right) \frac{\partial T}{\partial y}\right]-K N u_{d} \frac{\pi R}{\ell L}\left(T_{o}-T\right)
$$

The boundary conditions are

$$
\begin{aligned}
& y=0, \quad T=T_{0} \\
& y=R, \quad \frac{\partial T}{\partial y}=0
\end{aligned}
$$

\subsection{Discussion of Thermally-Developed Flow}

Fully developed flows are usually classified as those where $\partial u / \partial x=0$. The parallel use of the condition $\partial \mathrm{T} / \partial \mathrm{x}=0$ to define thermally-developed flow leads to the conclusion that the flow must be adiabatic, which is certainly not an interesting heat transfer problem. However, an asymptotic thermal state does exist which greatly simplifies the heat transfer problem and which is applicable to many problems of practical interest. Thermally-developed flows are characterized by convective heat transfer coefficients, $\bar{h}$, which are independent of the streamwise coordinate, $x$. 
The convective heat transfer coefficient is defined as

$$
\dot{q}_{0}=\bar{h}\left(T_{0}-T_{m}\right)
$$

where $T_{m}$ is the mixed-mean temperature for a rough surface. The wall heat flux can be expressed as the sum of heat transfer to the smooth wall plus heat transfer to the roughness elements:

$$
\dot{q}_{0}=-\left.K \beta_{y}(0) \frac{\partial T}{\partial y}\right|_{y=0}+\frac{\pi K}{\ell L} \int_{0}^{k} N u_{d}\left(T_{0}-T\right) d y
$$

Combining equations (18) and (19) gives

$$
\bar{h}\left(T_{0}-T_{m}\right)=-\left.K \beta_{y}(0) \frac{\partial T}{\partial y}\right|_{y=0}+\frac{\pi K}{\ell L} \int_{0}^{k} N u_{d}\left(T_{0}-T\right) d y
$$

Performing a scale analysis on equation (20), where $\Delta \mathrm{T}$ is the temperature scale and $\Delta$ is the $y$-length scale for the thermal boundary layer, gives the scale balance

$$
\bar{h} \Delta T \sim K \beta_{y}(0) \frac{\Delta T}{\Delta}, \frac{\pi K}{\ell L} \overline{N u}_{d} \Delta T k
$$

If the roughness effect is negligible,

$$
\bar{h} \sim \frac{K}{\Delta}
$$

and thr $\quad \mathrm{y}$ is thermally-developed with $\overline{\mathrm{h}}=$ constant when the $\mathrm{y}$-length scale becomes constant. In the case of pipe flow, the thermal boundary-layer thickness becomes constant when $\Delta \rightarrow R$. Figure 2 shows this concept for an isothermal flow that is subjected to a sudden change in thermal boundary condition at $\mathrm{x}=0$. becomes

If the roughness effects are dominant, the scale balance from equation (21)

$$
\bar{h} \sim \frac{\pi K}{\ell L} \overline{N u}_{d} k
$$




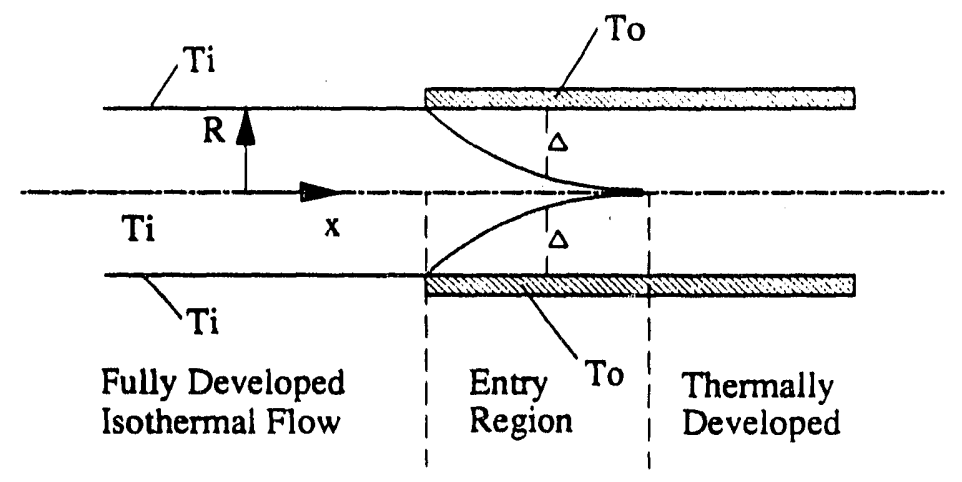

Fig. 2. Schematic diagram illustrating the idea of thermally developed flow.

Under the assumption of constant property, incompressible flow, the average Nusselt number $\overline{N u}_{d}$ is only a function of the flow field and is, therefore, constant for fully developed flow. If the roughness geometry parameters $(k, l, L)$ are not functions of $\mathrm{x}$, the roughness dominated case becomes thermally developed immediately--at least in the order of magnitude scale analysis sense--since there is no $x$-dependence in equation (23). This conclusion is substantiated by experimental observation, and it is often taken as an empirical fact without theoretical treatment (see Dipprey and Sabersky, 1963, for example).

For smooth walls, another statement of the thermally developed condition is that the nondimensional temperature

$$
\theta=\frac{T_{o}-T}{T_{0}-T_{m}}
$$

is not a function of $\mathbf{x}$; that is, $\partial \theta / \partial x=0$. Again, this is often treated as an empirical fact for roughness-dominated flows as well. However, since this property of thermally developed flows is necessary for the solution procedure used in this work, we will investigate the rough-wall case theoretically.

For the roughness-dominated flows, equation (20) reduces to

$$
\bar{h}\left(T_{o}-T_{m}\right)=\frac{\pi K}{\ell L} \int_{o}^{k} N u_{d}\left(T_{o}-T\right) d y
$$


or

$$
\bar{h}=\frac{\pi K}{l L} \int_{0}^{k} N u_{d} \theta d y
$$

If $\bar{h}=$ constant, $\mathrm{Nu}_{d} \neq f(x)$, and $(k, \ell, L) \neq f(x)$, it follows that $\theta \neq f(x)$ below the crests of the roughness elements.

The usual smooth-wall arguments apply in a slightly modified form for the region above the crests of the elements. In turbulent flows, the region near $a$ wall, $y / R$ $\ll 1$, can be approximated as a region of constant shear and heat flux. For a position $\mathrm{Y}$ just above the roughness, we can then write

$$
\dot{q}_{o}=-\left.\left[\left(K+K_{\mathrm{r}}\right) \frac{\partial T}{\partial y}\right]\right|_{\gamma}=\bar{h}\left(T_{o}-T_{m}\right)
$$

Rearranging

$$
\frac{\left.\left[\left(1+\frac{K_{T}}{K}\right) \frac{\partial T}{\partial y}\right]\right|_{Y}}{T_{0}-T_{m}}=-\frac{\bar{h}}{K}=\text { constant }
$$

This implies that

$$
\frac{\left(1+\frac{K_{T}}{K}\right) \frac{\partial T}{\partial y}}{T_{0}-T_{m}}=f(y)
$$

is at most a function of $y$. For fully developed velocity profiles and constant turbulent Prandtl numbers, $\mathrm{K}_{\mathrm{T}} / \mathrm{K}$ is at most a function of $\mathrm{y}$; so

$$
\frac{\frac{\partial T}{\partial y}}{T_{o}-T_{m}}=f_{2}(y)
$$


or

$$
-\frac{\partial \theta}{\partial y}=f_{2}(y)
$$

Integrating gives

$$
\theta=f_{3}(y)+f_{4}(x)
$$

Evaluating at $\mathrm{y}=\mathrm{R}$ gives

$$
\theta(x, R)=\frac{T_{0}-T_{c}}{T_{0}-T_{m}}=f_{3}(R)+f_{4}(x)
$$

From a scale analysis viewpoint, $\left(T_{0}-T_{c}\right)-\left(T_{0}-T_{m}\right)$, and, therefore, $f_{4}(x) \sim$ constant.

Alternately, the mean value of the nondimensional temperature, $\theta_{\mathfrak{m}}$, must equal unity

$$
\theta_{m}=1=2 \int_{0}^{1} \beta_{x} \tilde{u}(1-\tilde{y}) \theta d \tilde{y}
$$

where $\tilde{u}=u / U_{m}$ and $\tilde{y}=y / R$. Writing the integral as a zonal integral gives

$$
1=2 \int_{0}^{k} \beta_{x} \tilde{u}(1-\tilde{y}) \theta d \tilde{y}+2 \int_{k}^{1} \tilde{u}(1-\tilde{y}) \theta d \tilde{y}
$$

From the discussion above, $\theta=f_{3}(y)+f_{4}(x)$ in the second integral; so

$$
\begin{aligned}
1= & 2 \int_{0}^{k} \beta_{x} \tilde{u}(1-\tilde{y}) \theta d \tilde{y}+2 \int_{\tilde{K}}^{1} \tilde{u}(1-\tilde{y}) f_{3}(\tilde{y}) d \tilde{y} \\
& +\left[2 \int_{\tilde{k}}^{1} \tilde{u}(1-\tilde{y}) d \tilde{y}\right] f_{4}(x)
\end{aligned}
$$

For fully developed flow, $\tilde{u}=\tilde{u}(y)$, and it has been previously shown, equation (26), that below $y=k, \theta=\theta(y)$. Therefore, all of the integrals in equation (36) are constants, and $\mathrm{f}_{4}(\mathrm{x})=$ constant. 
For roughness-dominated flows and for flows with negligible roughness, thermally developed implies $\partial \theta / \partial x=0$. For the constant wall heat flux and constant wall temperature boundary conditions, this property leads to simplified energy equations as discussed in the following sections.

\subsection{Constant Wall Heat Flux}

The constant heat flux boundary condition is often encountered in practice. It occurs in counterflow heat exchangers with matched thermal capacities and in electrical heating applications. The electrically heated constant heat flux boundary condition is a widely encountered arrangement in experimental research facilities.

The pipe Nusselt number is defined as

$$
N u=\frac{2 R \dot{q}_{0}}{K\left(T_{0}-T_{m}\right)}=\frac{2 R \bar{h}}{K}
$$

For constant $\dot{\mathrm{q}}_{\mathrm{o}}$, constant $\overline{\mathrm{h}}$, and $\partial \theta / \partial \mathrm{x}=0$, it can be shown that

$$
\frac{\partial T}{\partial x}=\frac{\partial T_{o}}{\partial x}=\frac{\partial T_{m}}{\partial x}=\frac{\alpha}{U_{m} R^{2}} N u\left(T_{o}-T_{m}\right)
$$

Substituting into equation (15) gives

$$
\begin{aligned}
\frac{1}{\alpha} \beta_{x} u \frac{\alpha}{U_{m} R^{2}} N u\left(T_{o}-T_{m}\right)= & \frac{1}{r} \frac{\partial}{\partial y}\left[r \beta_{y}\left(1+\frac{K_{T}}{K}\right) \frac{\partial T}{\partial y}\right] \\
& +\frac{1}{r} N u_{d} \frac{\pi R}{\ell L}\left(T_{o}-T\right)
\end{aligned}
$$

Using the nondimensional variables $\tilde{u}=u / U_{m}, \tilde{y}=y / R, \tilde{r}=r / R=1-\tilde{y}, \tilde{\imath}=\ell / R$, and $\tilde{L}=L / R$, substituting, and rearranging gives the ordinary differential equation

$$
\beta_{x} \tilde{u} N u=-\frac{1}{\tilde{r}} \frac{d}{d \tilde{y}}\left[\tilde{r} \beta_{y}\left(1+\frac{K_{T}}{K}\right) \frac{d \theta}{d \tilde{y}}\right]+\frac{1}{\tilde{r}} N u_{d} \frac{\pi \theta}{\tilde{l} \tilde{L}}
$$


The boundary conditions are

$$
\begin{aligned}
& \tilde{y}=0, \quad \theta=0 \\
& \tilde{y}=1, \quad \frac{d \theta}{d \tilde{y}}=0
\end{aligned}
$$

\subsection{Constant Wall Temperature}

The constant wall temperature boundary condition is encountered in practice in the important applications of condensers and evaporators. Because of experimental difficulties, it is not often found in pipe flow experiments.

For constant $T_{0}, \partial \theta / \partial x=0$ implies

$$
\frac{\partial T}{\partial x}=\theta \frac{\partial T_{m}}{\partial x}=\theta \frac{\alpha}{U_{m} R^{2}} N u\left(T_{o}-T_{m}\right)
$$

and the energy equation becomes the ordinary differential equation

$$
\beta_{x} \tilde{u} \theta N u=-\frac{1}{\tilde{r}} \frac{d}{d \tilde{y}}\left[\tilde{r} \beta_{y}\left(1+\frac{K_{T}}{K}\right) \frac{d \theta}{d \tilde{y}}\right]+\frac{1}{\tilde{r}} N u_{d} \frac{\pi \theta}{\tilde{\ell} \tilde{L}}
$$

The boundary conditions are

$$
\begin{aligned}
& \ddot{y}=0, \theta=0 \\
& \tilde{y}=1, \frac{d \theta}{d \tilde{y}}=0
\end{aligned}
$$




\section{SECTION III}

\section{SOLUTION PROCEDURE}

Under the assumption of constant property, incompressible flow the momentum equation is independent of the temperature field and can be solved separately. In this work the momentum equation is solved for the velocity profile and that solution is then used in the energy equation solver.

\subsection{Momentum Equation Solution}

The momentum equation (7) is rearranged by defining the friction factor, $f_{f}$, such that

$$
\frac{d P}{d x}=-\rho f_{f} \frac{U_{m}^{2}}{R}
$$

and the eddy viscosity parameter, L*, such that

$$
L * \tilde{r} \beta_{y}\left(1+\frac{\mu_{T}}{\mu}\right)
$$

Substituting and rearranging gives, with prime denoting differentiation with respect to $\tilde{y}$,

$$
\tilde{u}^{\prime \prime}+\frac{L^{*}}{L^{*}} \tilde{u}^{\prime}-\left(\frac{1}{4 L^{*}} \operatorname{Re}_{D} \frac{\tilde{d}}{\tilde{L} \tilde{L}} C_{D} \tilde{u}\right) \tilde{u}+\frac{1}{2 L^{*}} \beta_{x} \operatorname{Re}_{D} f_{f}(1-\tilde{y})=0
$$

where $\mathrm{Re}_{\mathrm{D}}$ is the pipe Reynolds number. The boundary conditions are

$$
\begin{aligned}
& \tilde{y}=0, \quad u=0 \\
& \tilde{y}=1, \quad \tilde{u}^{\prime}=0
\end{aligned}
$$


The blockage factors for roughness elements with circular cross section are given by Scaggs et al. (1988) to be

$$
\beta_{y}=\beta_{y}=1-\frac{\pi \tilde{d}^{2}}{4 \tilde{l} \tilde{L}(1-\tilde{y})}
$$

The nondimensional element diameter can be expressed in terms of the relative roughness geometry

$$
\tilde{d}=f\left(\tilde{d}_{\omega}, \tilde{k}, \tilde{y}\right)
$$

where $d_{0}$ is the element base diameter and $k$ is the height.

The eddy viscosity is modeled with a two-band algebraic model taken from Kays and Crawford (1980). Near the wall a Prandtl mixing-length model with van Driest damping is used

$$
\begin{aligned}
& \frac{\mu_{T}}{\mu}=\frac{1}{2} \operatorname{Re}_{D} \tilde{\ell}_{m}^{2}\left|\frac{\partial \tilde{u}}{\partial \tilde{y}}\right| \\
& \tilde{l}_{m}=0.4 \tilde{y}\left[1-\exp \left(\frac{-\frac{1}{2} \operatorname{Re}_{D} \sqrt{\frac{f_{f}}{2} \tilde{y}}}{26}\right)\right]
\end{aligned}
$$

and in the turbulent core of the pipe

$$
\frac{\mu_{T}}{\mu}=0.4 \frac{1}{2} R e_{D} \frac{\sqrt{f_{f} / 2}}{6}
$$

The boundary between the domains of equations (54) and (55) is taken to be the point where they give the same value of $\mu_{\mathrm{T}} / \mu$. 
Following Taylor et al. (1984), the local element drag coefficient is expressed in terms of the local element Reynolds number, $\mathrm{Re}_{\mathrm{d}}$, as

$$
\begin{aligned}
& C_{D}=\left(\frac{R e_{d}}{1000}\right)^{-0.125} ; C_{D}>0.6 \\
& C_{D}=0.6 ; \text { otherwise }
\end{aligned}
$$

where $R e_{d}=\frac{1}{2} R e_{D} \tilde{d} \tilde{u}$.

Finally the velocity profile must satisfy the global conservation of mass

$$
\tilde{u}_{m}=1=2 \int_{0}^{1} \beta_{x} \tilde{u}(1-\tilde{y}) d \tilde{y}
$$

Given the pipe Reynolds number, $\operatorname{Re}_{\mathrm{D}}$, and the relative roughness $(\tilde{d}, \tilde{k}, \tilde{\ell}, \tilde{L})$, we can solve for $\mathrm{f}_{\mathrm{f}}$ and $\tilde{u}(y)$ using the following procedure:

1) Assume a value of $\mathrm{f}_{\mathrm{f}}$ and compute $\tilde{u}(y)$ using the finite difference procedure in Appendix I.

2) Find values of $f_{f}$ such that the corresponding values of $\tilde{u}_{m}$ bound 1 .

3) Use false position to solve for $\mathrm{f}_{\mathrm{f}}$ such that $\tilde{u}_{m}=1$.

\subsection{Energy Equation--Constant Wail Heat Flux}

Defining the eddy conductivity parameter, $L^{* *}$, such that

$$
L^{* *}=\tilde{r} \beta_{y}\left(1+\frac{K_{T}}{K}\right)=\tilde{r} \beta_{y}\left(1+\frac{\mu_{T}}{\mu} \frac{\operatorname{Pr}}{P r_{T}}\right)
$$

and the temperature profile, $\tilde{\theta}$, such that

$$
\tilde{\theta}=\frac{\theta}{N u}
$$


the energy equation (40) becomes

$$
\tilde{\theta}^{\prime \prime}+\frac{L^{* *^{\prime}}}{L^{* *}} \tilde{\theta}^{\prime}-N u_{d} \frac{\pi \tilde{\theta}}{\tilde{l} \tilde{L} L^{* *}}+\beta_{x} \frac{\tilde{u}(1-\tilde{y})}{L^{* *}}=0
$$

with boundary conditions

$$
\begin{aligned}
& \tilde{y}=0, \quad \tilde{\theta}=0 \\
& \tilde{y}=1, \quad \tilde{\theta}^{\prime}=0
\end{aligned}
$$

The eddy viscosity, $\mu_{\mathrm{T}} / \mu$, and the velocity profile, $\tilde{u}(\tilde{y})$, are determined in the preceding momentum equation solution. The turbulent Prandtl number is taken to be constant following Kays and Crawford (1980)

$$
\begin{aligned}
& \operatorname{Pr}_{t}=0.9 \quad \operatorname{Pr}<1 \\
& \operatorname{Pr}_{t}=1.0 \quad \operatorname{Pr} \succ 1
\end{aligned}
$$

The local element Nusselt number is expressed in terms of the local element Reynolds number, $\mathrm{Re}_{\mathrm{d}}$, following Hosni et al. (1989) and Taylor et al. (1984) as

$$
\begin{aligned}
& N u_{d}=1.7 \operatorname{Re}_{d}^{0.49} \operatorname{Pr}^{0.4} ; \operatorname{Re}_{d}<2,500 \\
& N u_{d}=0.963 \operatorname{Re}_{d}^{0.6} \operatorname{Pr}^{0.4} ; 2,500 \leq \operatorname{Re}_{d}<200,000 \\
& N u_{d}=0.06 \operatorname{Re}_{d}^{0.94} \operatorname{Pr}^{0.4} ; \operatorname{Re}_{d}<200,000
\end{aligned}
$$

where $R e_{d}=1 / 2 R e_{D} \tilde{d} \tilde{u}$. The expressions in equation (64) are a combination of Hosni et al. and Taylor et al. Hosni's calibration expressions are the more extensive of the two but are limited to values of $\mathrm{Re}_{\mathrm{d}}<2,500$.

Equation (60) can be solved directly for $\tilde{\theta}$ using the finite difference method given in Appendix I. The Nusselt number is determined using the requirement that the mean value of the nondimensional temperature must be equal to 1 .

$$
\theta_{m}=N u \tilde{\theta}_{m}=1=2 N u \int_{0}^{1} \beta_{x} \tilde{u}(1-\tilde{y}) \tilde{\theta} d \bar{y}
$$


or

$$
N u=\frac{1}{\tilde{\theta}_{m}}
$$

\subsection{Energy Equation--Constant Wall Temperature}

Using the same models for eddy conductivity and local element Nusselt number as in Section 3.2, the energy equation for constant wall temperature is

$$
\tilde{\theta}^{\prime \prime}+\frac{L^{* *}}{L^{* *}} \tilde{\theta}^{\prime}-N u_{d} \frac{\pi \tilde{\theta}}{\tilde{l} \tilde{L} L^{* *}}+\beta_{x} \frac{\tilde{u}(1-\tilde{y})}{L^{* *}} \theta=0
$$

with boundary conditions

$$
\begin{aligned}
& \tilde{y}=0, \quad \tilde{\theta}=\theta=0 \\
& \tilde{y}=1, \quad \tilde{\theta}^{\prime}=\theta^{\prime}=0
\end{aligned}
$$

Equation (67) cannot be solved directly for $\tilde{\theta}$ since it also contains $\theta$. In orcier to obtain a solution, an iterative procedure is used. An initial profile is assumed for $\theta=\theta_{1}^{*}$. An excellent starting profile is the constant heat flux profile from Section 3.2. Then the modified equation

$$
\tilde{\theta}_{1}^{\prime \prime}+\frac{L^{* *}}{L^{* *}} \tilde{\theta}_{1}^{\prime}-N u_{d} \frac{\pi \tilde{\theta}_{1}}{\tilde{l} \tilde{L} L^{* *}}+\beta_{x} \frac{\tilde{u}(1-\bar{y})}{L^{* *}} \theta_{1}^{*}=0
$$

is solved for $\tilde{\theta}_{1}$ using the finite difference method in Appendix I. The pipe Nusselt number is computed for the definition of $\theta_{\mathrm{m}}$

$$
N u_{1}=\frac{1}{\tilde{\theta}_{1, m}}
$$

The process is repeated using $\theta_{i}^{*}=N u_{i-1} \tilde{\theta}_{i-1}$ until a consistent value of $\mathrm{Nu}$ is obtained. Usually, fewer than four iterations are required. 


\section{SECTION IV}

\section{COMPARISON OF COMPUTATIONS AND EXPERIMENTS}

In this section, the predictions are compared with the appropriate experimental cases from the following list of references:

1. Dipprey and Sabersky (1963)

2. Takahashi et al. (1985)

3. Gowen and Smith (1968)

4. Cope (1945)

Appropriate cases are those where the flow can be reasonably approximated as circular pipe turbulent flow with protruding three-dimensional roughness elements (not dimples) with aspect ratios of order 1 . Geometries which do not fit this description are discussed with respect to the appropriateness of extending the present method.

Before these comparisons were made, the computer program and solution procedures were validated by comparing with classic results for laminar and turbulent smooth-wall cases and by comparison with the friction factor experiments of Scaggs et al. (1988).

\subsection{Smooth Wall}

The solution procedures and computer programs can be used to predict smoothwall pipe friction factor and Nusselt number by specifying a vanishingly small roughness. In addition, the programs assume laminar flow, $\downarrow_{T}=0$, for all cases where $\operatorname{Re}_{\mathrm{D}}<2000$.

Table 1 shows a comparison of the present predictions and the classic solutions (Kays and Crawford, 1980) for smooth, laminar cases. The classic friction

Table 1. Laminar flow comparisons

Present predictions $\quad$ Classic solutions

$\begin{array}{ccccccc}\mathrm{Re}_{D} & \mathrm{f}_{\mathrm{f}} & \mathrm{Nu}_{\mathrm{H}} & \mathrm{Nu}_{\mathrm{T}} & \mathrm{f}_{\mathrm{f}} & \mathrm{Nu}_{\mathrm{H}} & \mathrm{Nu}_{\mathrm{T}} \\ 1000 & 0.0160 & 4.364 & 3.654 & 0.016 & 4.364 & 3.658 \\ 2000 & 0.0080 & 4.364 & 3.654 & 0.008 & 4.364 & 3.658\end{array}$


factor solution is $f_{f}=16 / R_{D}$. The classic solution for the Nusselt number for constant wall heat flux, $\mathrm{Nu}_{\mathrm{H}}$, is a constant value of 4.364 and the one for a constant wall temperature is a constant value of 3.658. The agreement is perfect for the direct solutions of $\mathrm{f}_{\mathrm{f}}$ and $\mathrm{Nu}_{\mathrm{H}}$ and exact within the convergence limits for the iterative solution of $\mathrm{Nu}_{\mathrm{T}}$.

This excellent agreement is expected since the present solutions for laminar flow are automated versions of the classic solutions. However, this test is important because it demonstrates that the computer programs are coded properly in all areas except the turbulence and roughness models.

Figure 3 shows comparisons of smooth-wall turbulent predictions with the data of Scaggs et al. (1988) for friction factor and with the Dittus-Boelter correlation for the Nusselt number. The Nusselt number predictions were made using a Prandtl number of 0.7 and the constant heat flux boundary condition. Turbulent flows are relatively insensitive to the choice of constant heat flux or constant temperature boundary conditions for Prandtl numbers of order one and greater. The agreement is seen to be excellent in both plots. This excellent agreement is also expected since the turbulence model that is used here was in effect derived from smooth-wall turbulent pipe flow data. This test demonstrates that the computer programs and solution procedures are working correctly in all aspects but the roughness model.

\subsection{Scaggs et al.}

Scaggs et al. (1988) present friction factor data for turbulent flow in pipes roughened with hemispheres and cones. Their experiments were conducted with water in nominally $50 \mathrm{~mm}$ pipes with a variety of roughness spacings and sizes. Figure 4 shows the roughness layout, and Table 2 summarizes the roughness dimensions.

Figures 5-7 show a comparison of the predictions with this data. The agreement is excellent. Just as with the smooth-wall comparisons in Section 4.1, this excellent agreeniont was expecied. The roughness model of Taylor et al. (1984), which is used here, was calibrated using the cone and spherical segment data of Schlichting (1936) and has previously been shown (Scaggs et al., 1988) to be in excellent agreement with this data. The purpose of these comparisons was to demonstrate that the computer programs and solution procedures used here are in agreement with the previous models and that the programs and procedures have been coded properly.

\subsection{Dipprey and Sabersky}

Dipprey and Sabersky (1963) presented an extensive set of heat transfer and fluid mechanics data for the flow of water through rough pipes. The rough tubes were 

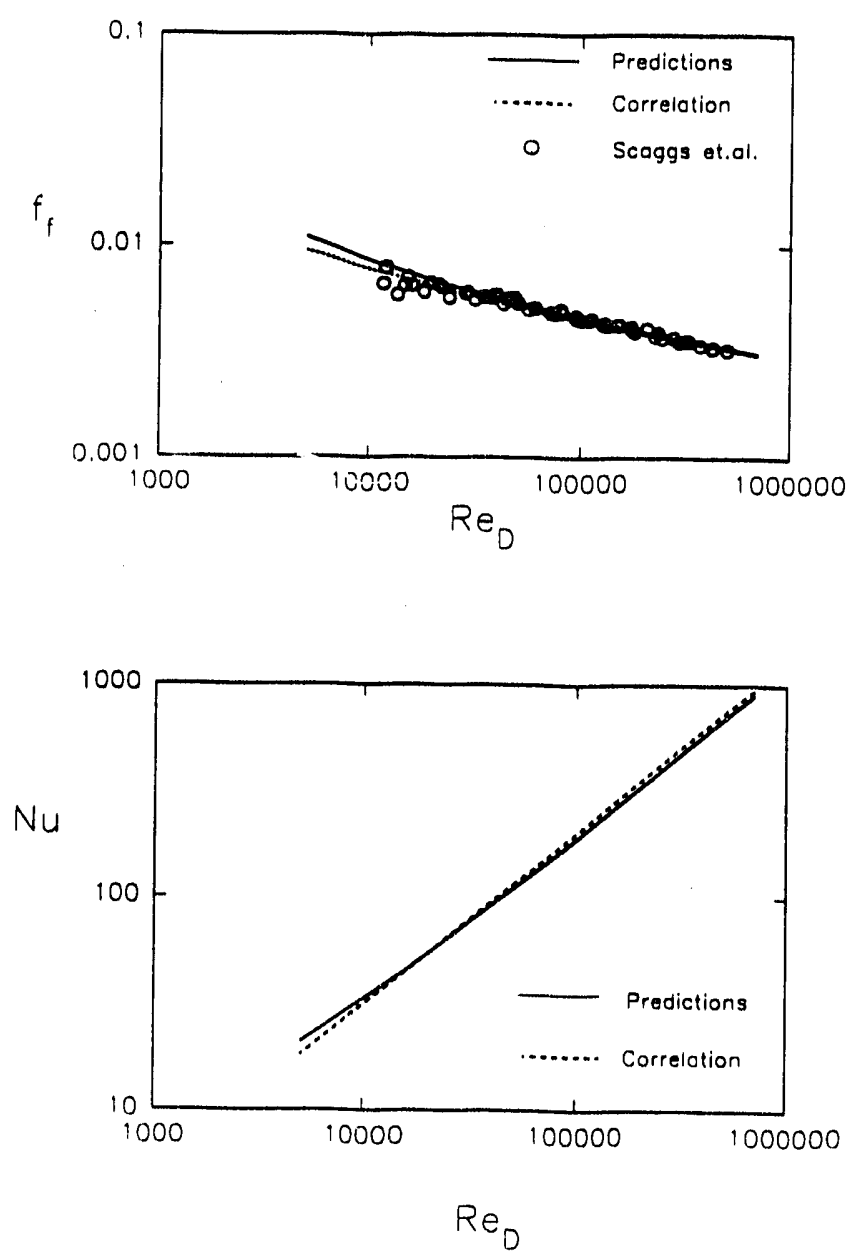

Fig. 3. Comparison of smooth-wall computations of friction factor and Nusselt number with accepted correlations and the data of Scaggs et al. (1988).

produced by electroplating nickel over mandrels coated with slosely spaced sand grains with a narrow grain size distribution. The mandrels were subsequently chemically dissolved leaving a pure nickel tube whose inside surface gave the general appearance of an array of close-packed sand grains. Three rough tubes were manufactured in this manner with inside diameters and equivalent sand-grain roughness factors of $D=9.75 \mathrm{~mm}$ and $\mathrm{k}_{\mathrm{s}} / \mathrm{D}=0.0024, \mathrm{D}=9.98 \mathrm{~mm}$ and $\mathrm{k}_{\mathrm{s}} / \mathrm{D}=$ 0.0138 , and $\mathrm{D}=10.13 \mathrm{~mm}$ and $\mathrm{k}_{\mathrm{s}} / \mathrm{D}=0.0488$. 


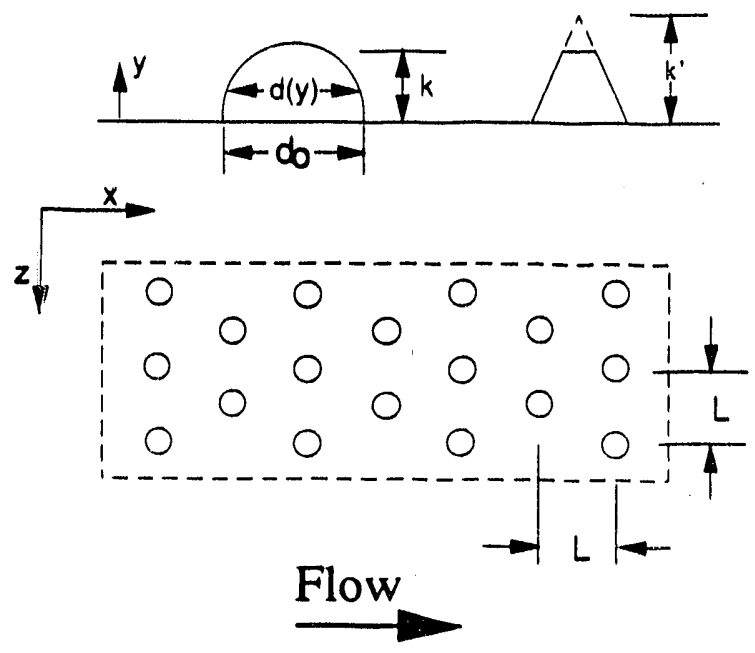

Fig. 4. Surface roughness geometry for the experiments of Scaggs et al. (1988).

Table 2. Ge(ometries of the roughness of Scaggs et al.

$\begin{array}{llllll} & \text { Pipe } & \text { Base } & \text { Element } & \text { Element } & \text { Projected } \\ \text { Surface } & \text { Diameter } & \text { Diameter } & \text { Spacing } & \text { Height } & \text { Height } \\ & D[\mathrm{~mm}] & d_{\mathrm{o}}[\mathrm{mm}] & \mathrm{L}=\ell[\mathrm{mm}] & \mathrm{k}[\mathrm{mm}] & \mathrm{k}^{\prime}[\mathrm{mm}]\end{array}$

Large

Hemispheres

$\begin{array}{llllll}\text { A-1 } & 51.46 & 2.55 & 5.10 & 1.27 & - \\ \text { A-2 } & 51.46 & 2.55 & 10.20 & 1.27 & - \\ \text { A-3 } & 51.54 & 2.55 & 20.25 & 1.27 & -\end{array}$

\section{Cones}

$\begin{array}{llllll}\text { A-4 } & 51.31 & 2.50 & 5.05 & 1.30 & 1.52 \\ \text { A-5 } & 51.40 & 2.55 & 10.10 & 1.30 & 1.52 \\ \text { A-6 } & 51.46 & 2.50 & 20.25 & 1.25 & 1.52\end{array}$

Small

Hemispheres

$\begin{array}{llllll}\text { B-1 } & 51.88 & 1.25 & 2.50 & 0.65 & - \\ \text { B-2 } & 51.54 & 1.25 & 5.05 & 0.60 & - \\ \text { B-3 } & 51.63 & 1.30 & 10.10 & 0.55 & -\end{array}$




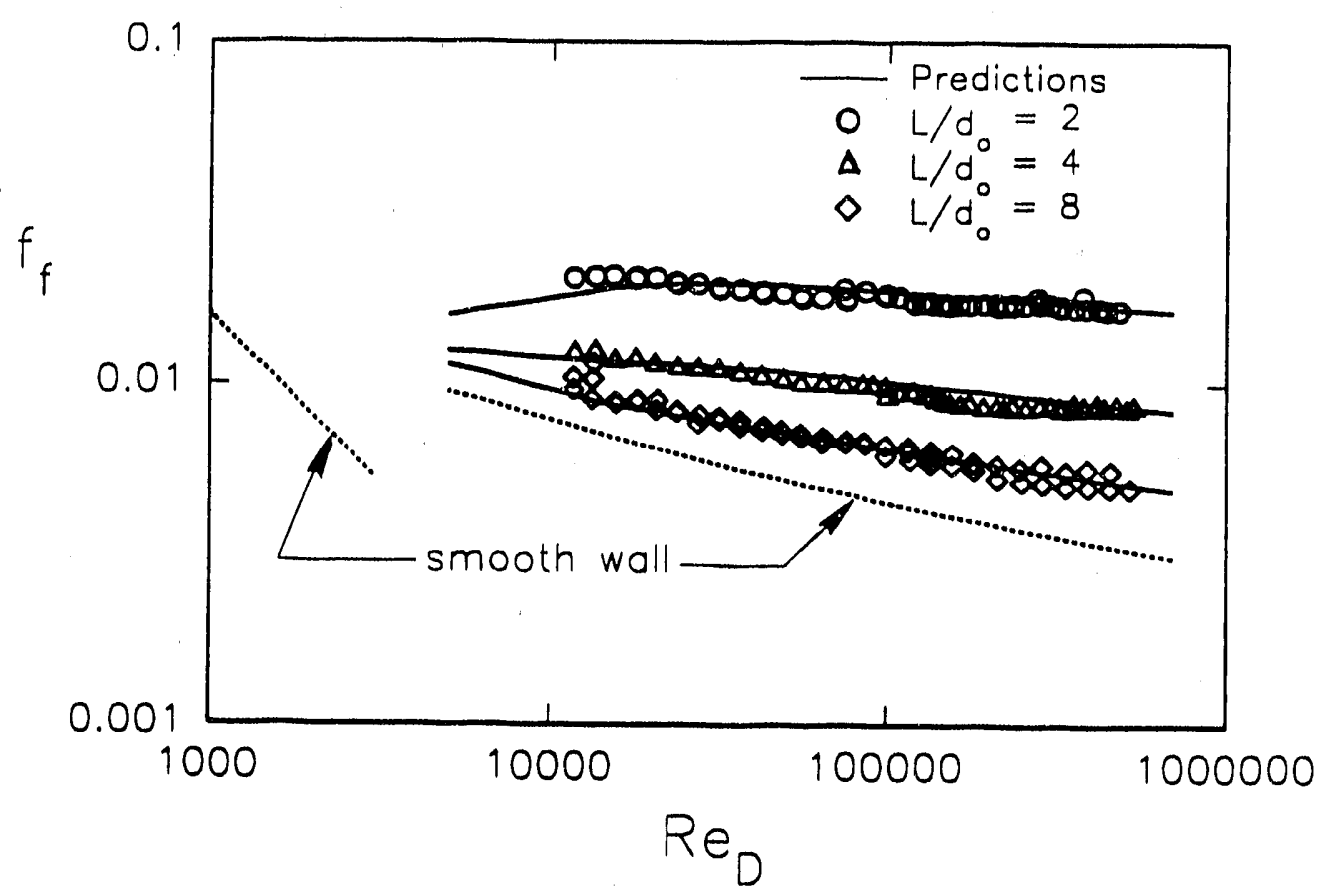

Fig. 5. Comparison of discrete element computations with the large hemisphere roughness data of Scaggs et al. (1988).

Dipprey and Sabersky did not report any measurement of the physical scale of the roughness. The equivalent sand-grain roughness values reported above were obtained by comparing the fully-rough friction factors with the correlations of Nikuradse (1933). Therefore, they are hydrodynamic parameters, not measures of the physical roughness size. Fortunately, since the surfaces were sand-grain-like, this length scale should be the same order as the physical length scale. Based on this and some numerical experiments, these rough surfaces were modeled as arrays of cones where the height equals the equivalent sand-grain roughness $\left(k=k_{\mathrm{s}}\right)$, the base diameter equals twice the sand-grain roughness $\left(d_{o}=2 k_{s}\right)$, and the spacing is a uniform square array $\left(L=l=2 d_{0}\right)$. Table 3 shows the rcughness model parameters used for these predictions. 


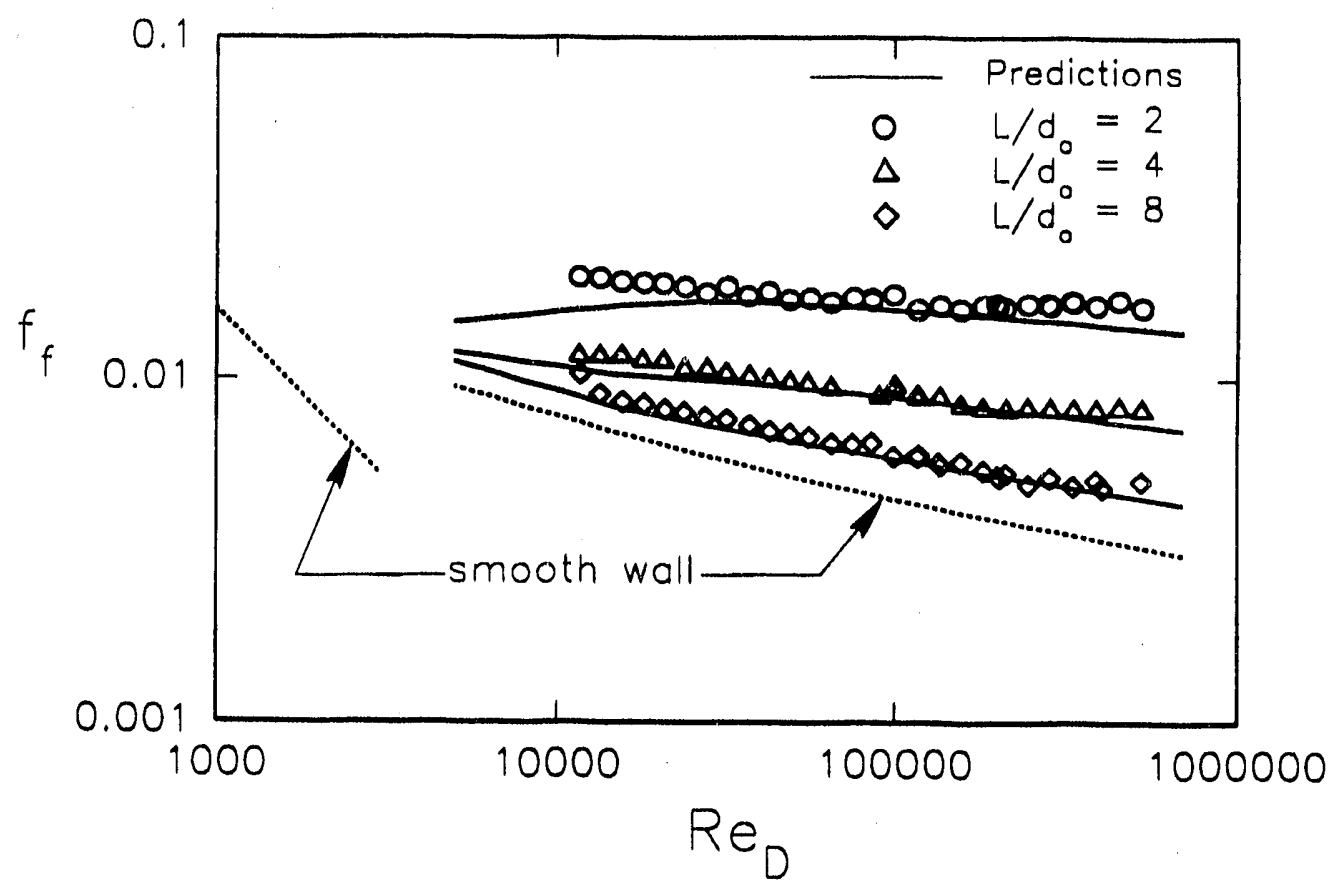

Fig. 6. Comparison of discrete element computations with the cone roughness of Scaggs et al. (1988).

Table 3. Geometries for the cone model for Dipprey and Sabersky's surfaces.

$\begin{array}{llllll}\text { Surface } & \begin{array}{l}\text { Pipe } \\ \text { Diameter } \\ \mathrm{D}[\mathrm{mm}]\end{array} & \begin{array}{l}\text { Base } \\ \text { Diameter } \\ \mathrm{d}_{\mathrm{o}}[\mathrm{mm}]\end{array} & \begin{array}{l}\text { Element } \\ \text { Spacing } \\ \mathrm{L}=\ell[\mathrm{mm}]\end{array} & \begin{array}{l}\text { Element } \\ \text { Height } \\ \mathrm{k}[\mathrm{mm}]\end{array} & \begin{array}{l}\text { Projecte } \\ \text { Height } \\ \mathrm{k}^{\prime}[\mathrm{mm}]\end{array} \\ \mathrm{D}-3 & 9.75 & 0.0467 & 0.0935 & 0.0234 & 0.0234 \\ \mathrm{C}-9 & 9.98 & 0.275 & 0.551 & 0.138 & 0.138 \\ \text { A-4 } & 10.13 & 0.989 & 1.978 & 0.494 & 0.494\end{array}$




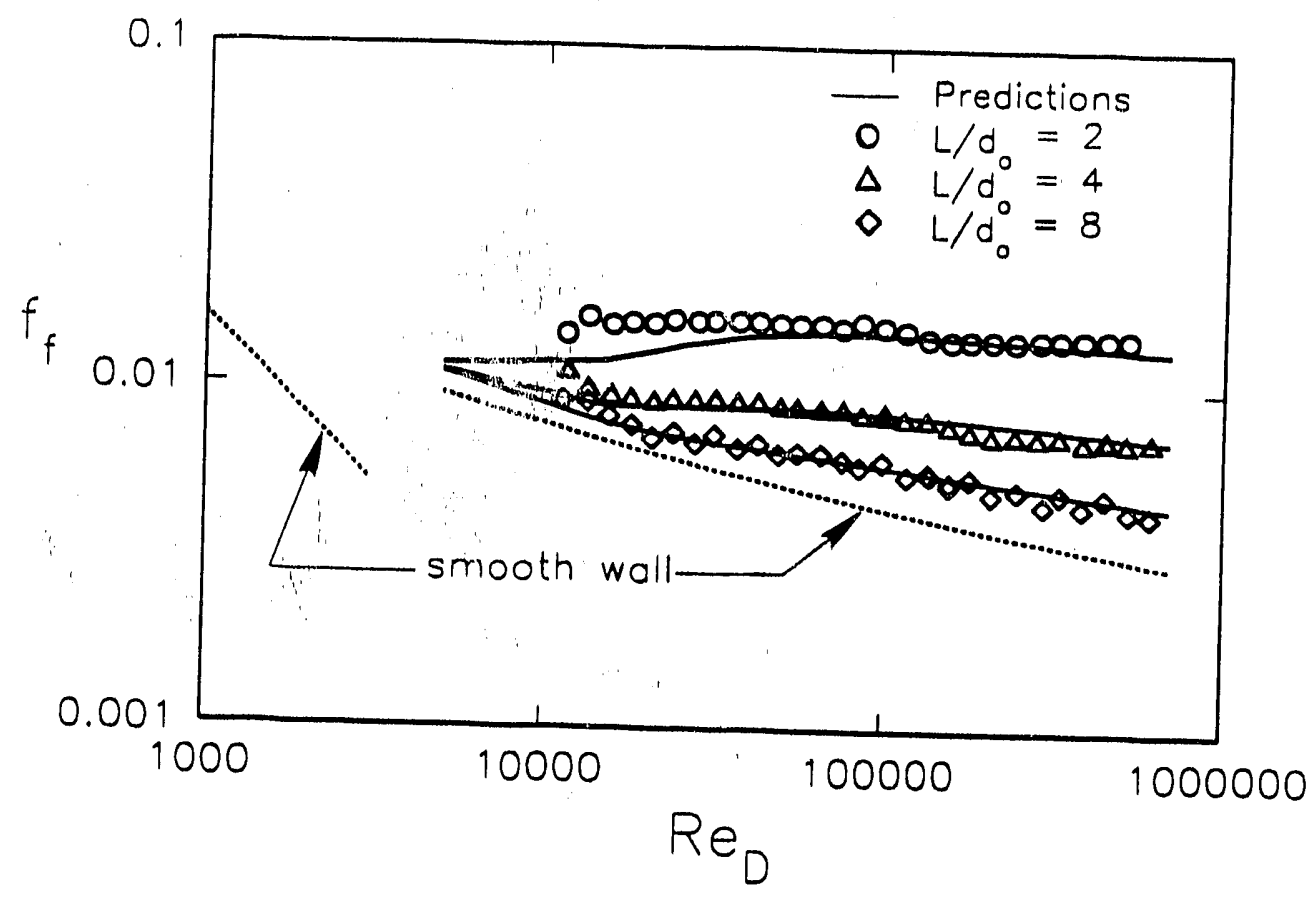

Fig. 7. Comparison of discrete elernent computations with the small hemisphere roughness of Scaggs et al. (1988).

The heat transfer experiments were conducted by electrically heating the nickel tubes. This resulted in a boundary condition which closely approximates a constant heat flux. The Prandtl numbers were varied by adjusting the mean temperature level of the experiment. The friction factor data were determined from pressure drop measurements. These experiments were taken with great care and are considered to be of high accuracy.

Figures 8-10 present the comparisons of the predictions and the experimental data for these cases. Part a) of the figures shows the friction factor comparisons and Part b) shows the Nusselt number comparisons. For clarity, only the cases for the lower and upper ends of the Prandtl number ranges are plotted in the Nusselt number graphs. Comparisons between predictions and experimental data at the intermediate Prandtl numbers exhibited similar agreement. A general inspection of the figures reveals excellent agreement for all cases.

Figure 8 presents the comparison for the smallest roughness. In this case, the flow is hydrodynamically smooth at low values of pipe Reynolds number, passes through the transitionally rough regime at the intermittent values of Reynolds number and approaches fully rough flow at the larger values of Reynolds number. The discrete element predictions capture all of this with no prior knowledge of the flow regime. In the Nusselt number plot, three symbols are shown at each $\operatorname{Re}_{\mathrm{D}}$ value. 

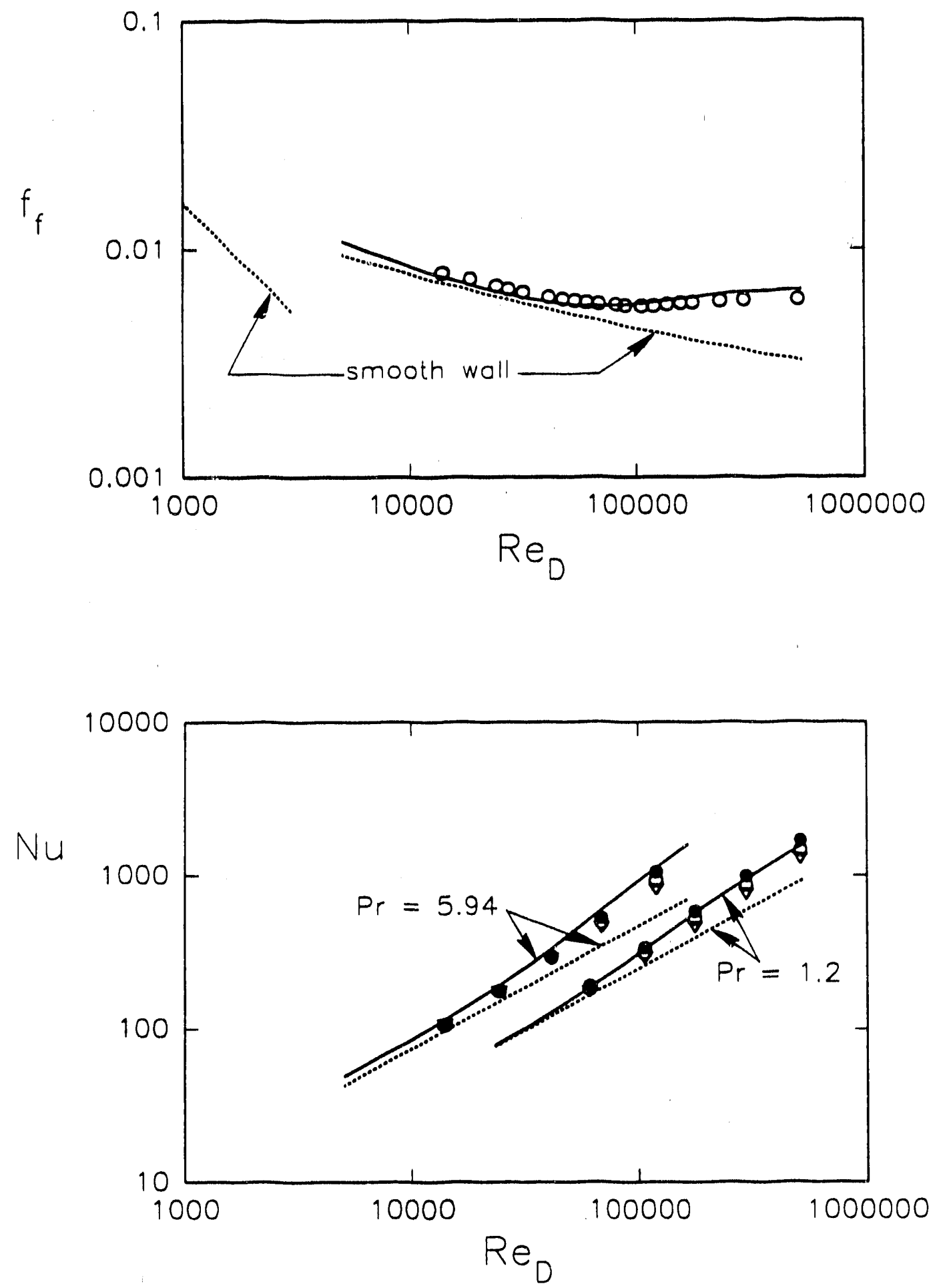

Fig. 8. Comparison of the discrete element computations with the data for tube D-3 of Dipprey and Sabersky (1963). 

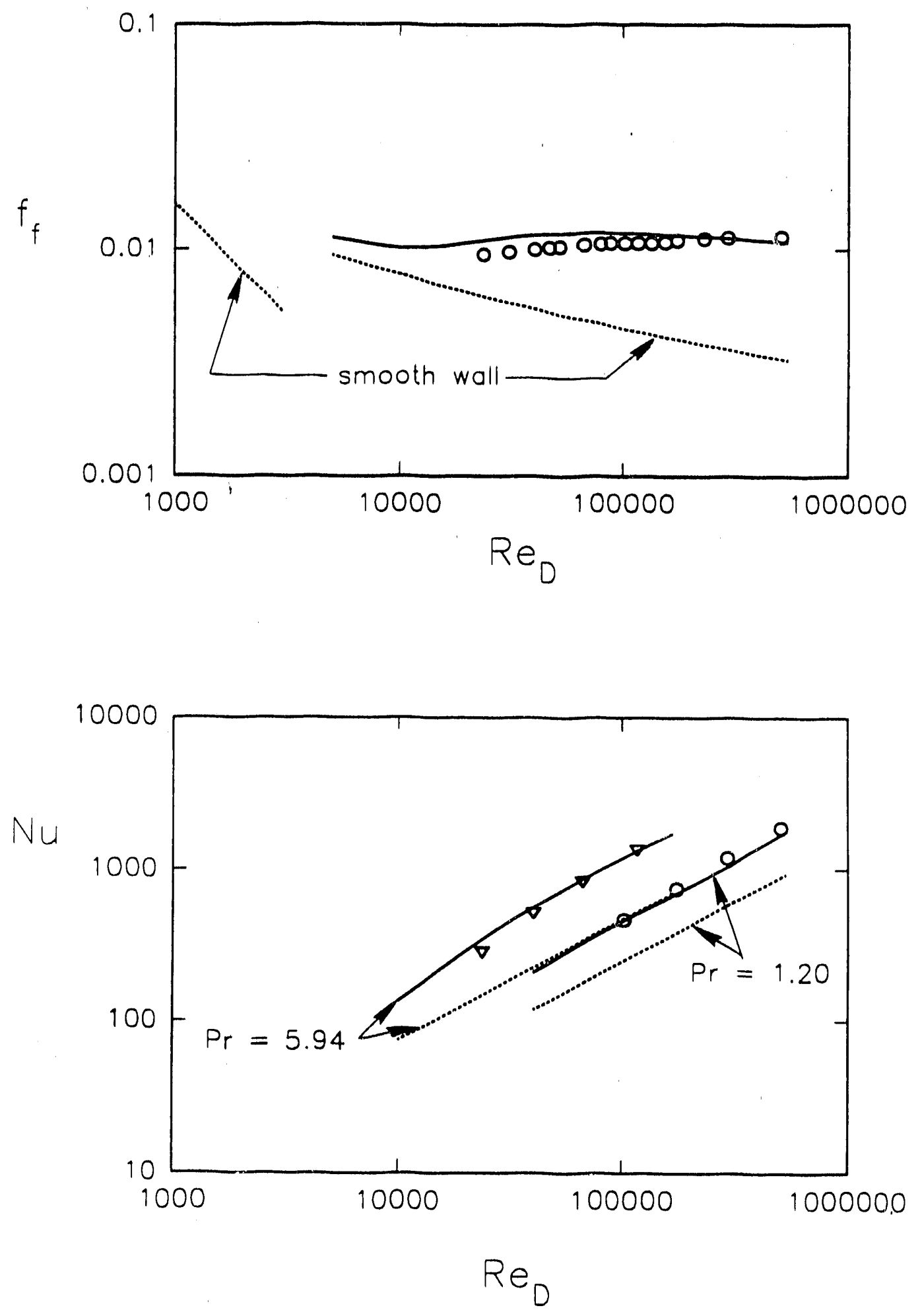

Fig. 9. Comparison of the discrete element computations with the data for tube C-9 of Dipprey and Sabersky (1963). 

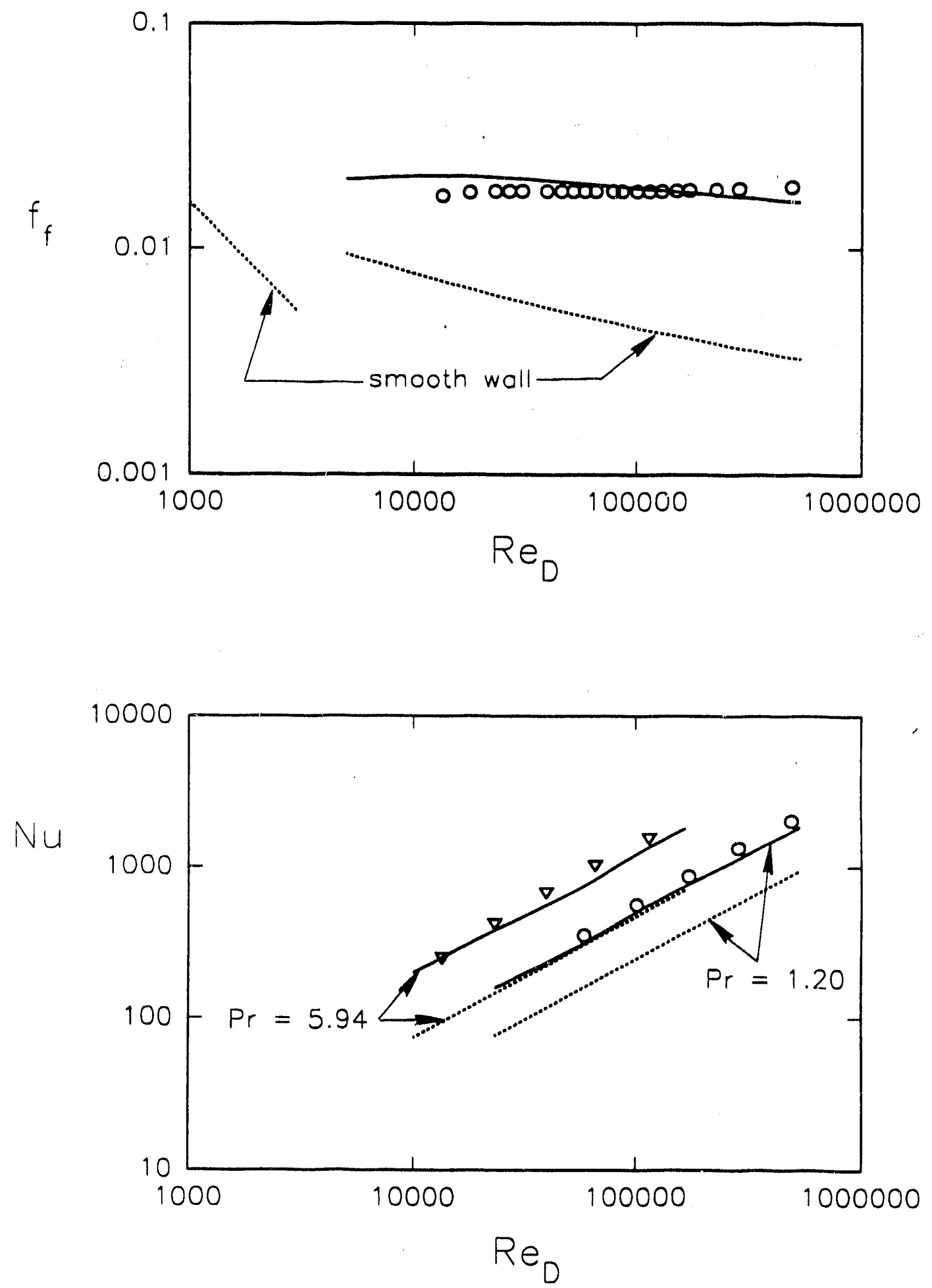

Fig. 10. Comparison of the discrete element computations with the data for tube A-4 of Dipprey and Sabersky (1963). 
These correspond to the values determined using three different wall thermocouples which were spaced around the tube circumference. A circumferential variation in wall temperature was observed only for this tube. Dipprey and Sabersky speculated that this variation was a result of small variations in the roughness.

Figure 9 includes data in both the transitionally-rough and fully-rough regimes, and Figure 10 includes data in only the fully-rough regime. In all of the cases the agreement is excellent.

The physical model used above contained a limited amount of freedom in that the modeler was free to select the dimensions of the physical model within fairly limited ranges. For example, we could have used cones spaced 1.5 base diarneters apart instead of 2. But a spacing of 5 base diameters apart would have been unreasonable given our knowledge of the nature of the surface. Howvever, the exact same physical model was used for all of the tubes with a single scaling factor.

\subsection{Takahashi et al.}

Takahashi et al. (1985) presented extensive fluid mechanics and heat transfer data from tubes having three-dimensional spiral ribs. They tested eleven different roughness geometries generated by a two-pass forging process. The tubes were roughened first with two-dimensional spiral ribs using a forging process, followed by another forging process which made rows of dents in the ribs. The resulting protrusions were called three-dimensional spiral ribs. For most of the tubes, the second forging process produced dents that were not as deep as the full rib height. These cases are not appropriate for comparison with the present prediction method since two-dimensional rib-type roughness, not three-dimensional distributed roughness, resulted.

However, for three of the tubes the second forging process did penetrate the full rib height, resulting in purely three-dimensional roughnesi elements. These cases were tubes A-3, A-6, and A-8 in Takahashi's numbering scheme. Figures 11-13 show plan views of these surfaces. In all cases the roughness elements are trapezoidal in crosssection, are oriented at an angle to the primary flow direction and form broken spiral ribs.

The heat transfer measurements were made using electrically heated pipes operating in the constant wall heat flux mode. The friction factors were determined from pressure drop measurements. The experiments seem to have teen carefully done, and the data are thought to be of good accuracy.

The discrete element model, as presently formulated, is limited to elements with circular cross-sections. As a first approximation for Takahashi's roughness, an array 


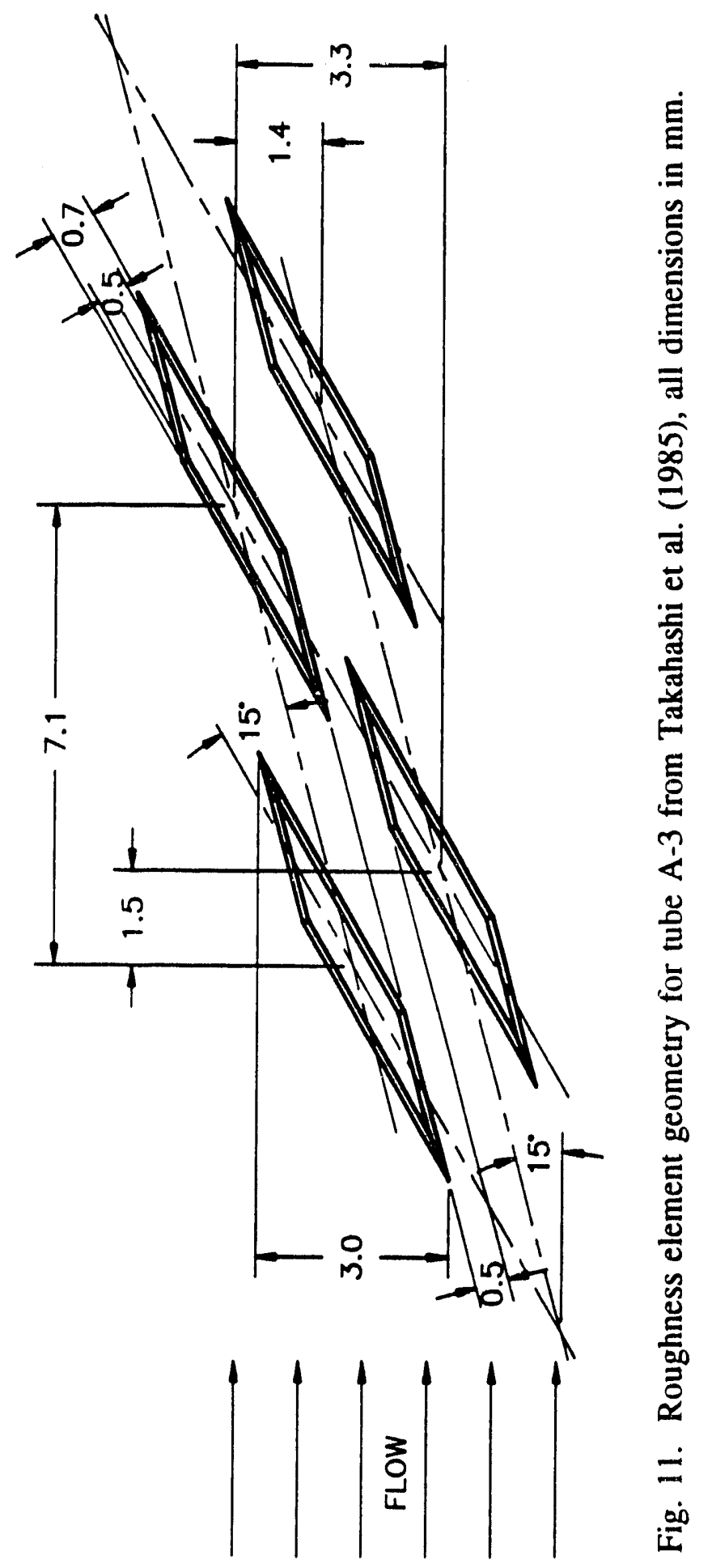




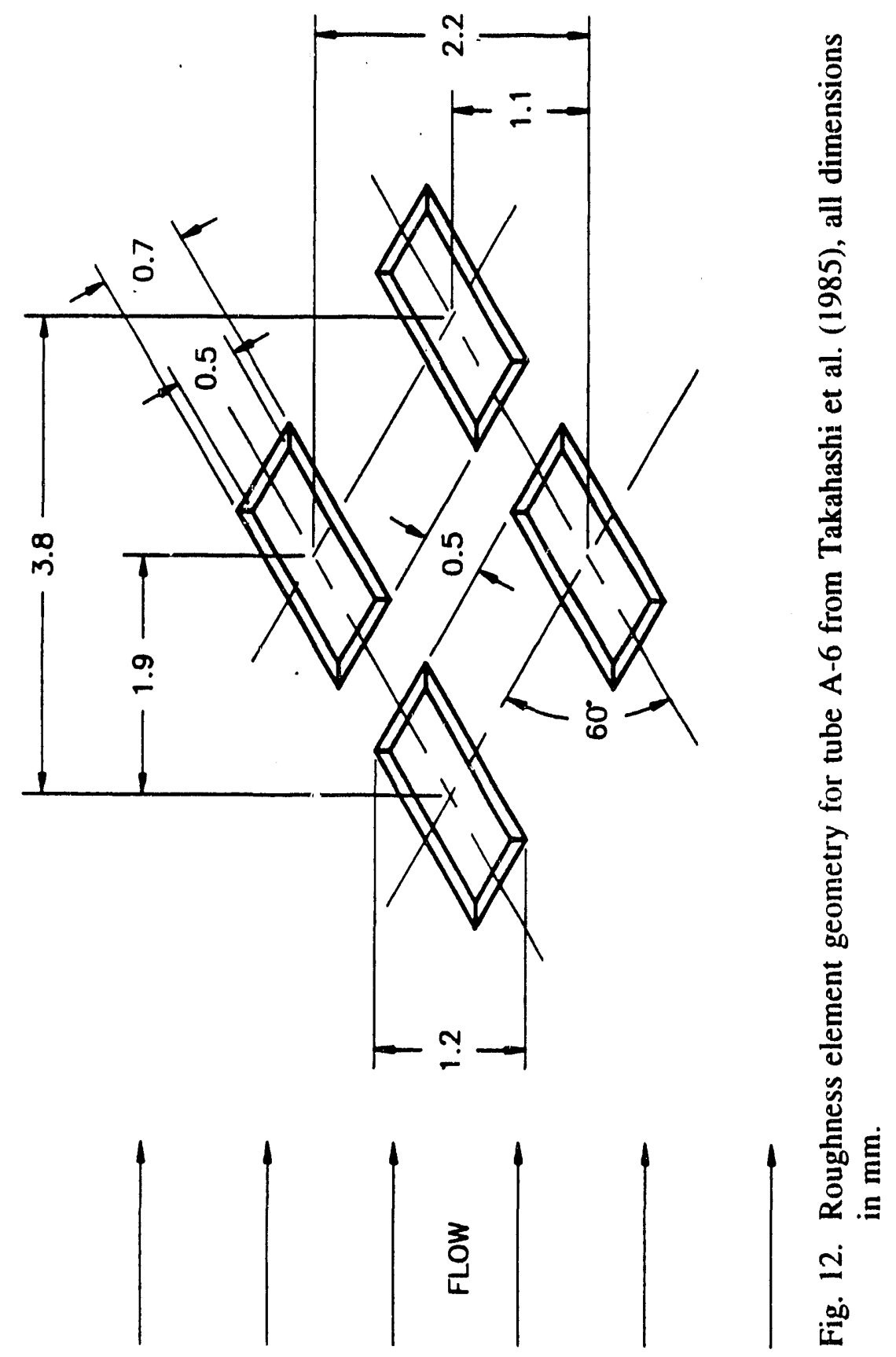




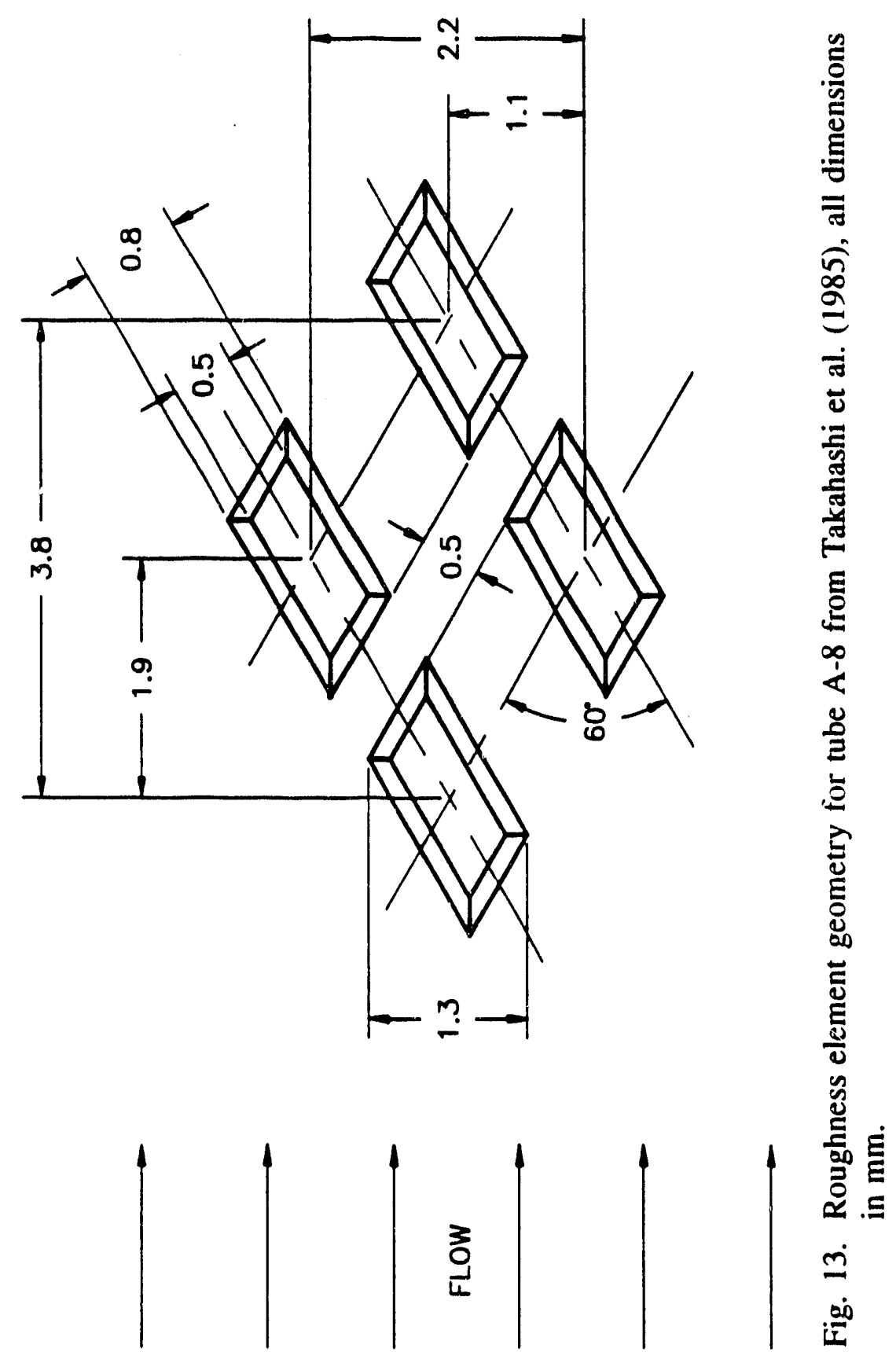


of truncated cones which gave the same projected frontal area for the primary flow direction was used. For tube A-3 in Figure 11 this resulted in a base diameter of $3.00 \mathrm{~mm}$. For all of the cases, this produced a large overprediction of both friction factor and Nusselt number. Subsequently, the roughness was modeled as an array of truncated cones with base diameters equal to the minor axis of the trapezoids. For tube A-3 in Figure 11 this would be a cone with a base diameter of $0.7 \mathrm{~mm}$. This produced excellent agreement for both friction factor and Nusselt number for all three cases. We interpret this to indicate that the flow in these tubes had a significant spiral component. Table 4 describes the cone roughness geometry used to model Takahashi's surfaces.

Figures 14-16 provide the comparisons of the experimental data and the predictions using this surface model. The ordinates in the Nusselt number graphs are plotted as $\mathrm{Nu} / \mathrm{Pr}^{0.4}$ because this is the way that Takahashi et al. present their data and because they did not specify the Prandtl numbers for the individual experimental runs. All of the computations were made with an assumed value of $\operatorname{Pr}=5.2$ and constant heat flux boundary conditions. The agreements are seen to be excellent in all cases except for the friction factor, which is slightly overpredicted in Figure 16 for tube A-8.

\section{$4.5 \quad$ Cope}

Cope (1941) reported heat transfer and friction factor data for pipes which were roughened with pyramids. These pyramids were formed in the pipe using a knurling process. His friction factors were determined from pressure drop measurements made between two total head probes on the centerline of the pipe and separated by the length of the working section. His heat transfer measurements were made in a parallel-flow heat exchanger apparatus.

Table 4. Geometries for the cone model for Takahashi et al.'s surfaces

$\begin{array}{llllll} & \text { Pipe } & \text { Base } & \text { Element } & \text { Element } & \text { Projected } \\ \text { Surface } & \text { Diameter } & \text { Diameter } & \text { Spacing } & \text { Height } & \text { Height } \\ & D[\mathrm{~mm}] & \mathrm{d}_{\mathrm{o}}[\mathrm{mm}] & \mathrm{L}, \ell[\mathrm{mm}] & \mathrm{k}[\mathrm{mm}] & \mathrm{k}^{\prime}[\mathrm{mm}]\end{array}$

$\begin{array}{llllll}\text { A-3 } & 13.9 & 0.7 & 7.1,3.3 & 0.3 & 5.6 \\ \text { A-6 } & 13.9 & 0.7 & 1.9,2.2 & 0.3 & 2.2 \\ \text { A-8 } & 13.9 & 0.8 & 1.9,2.2 & 0.5 & 2.4\end{array}$



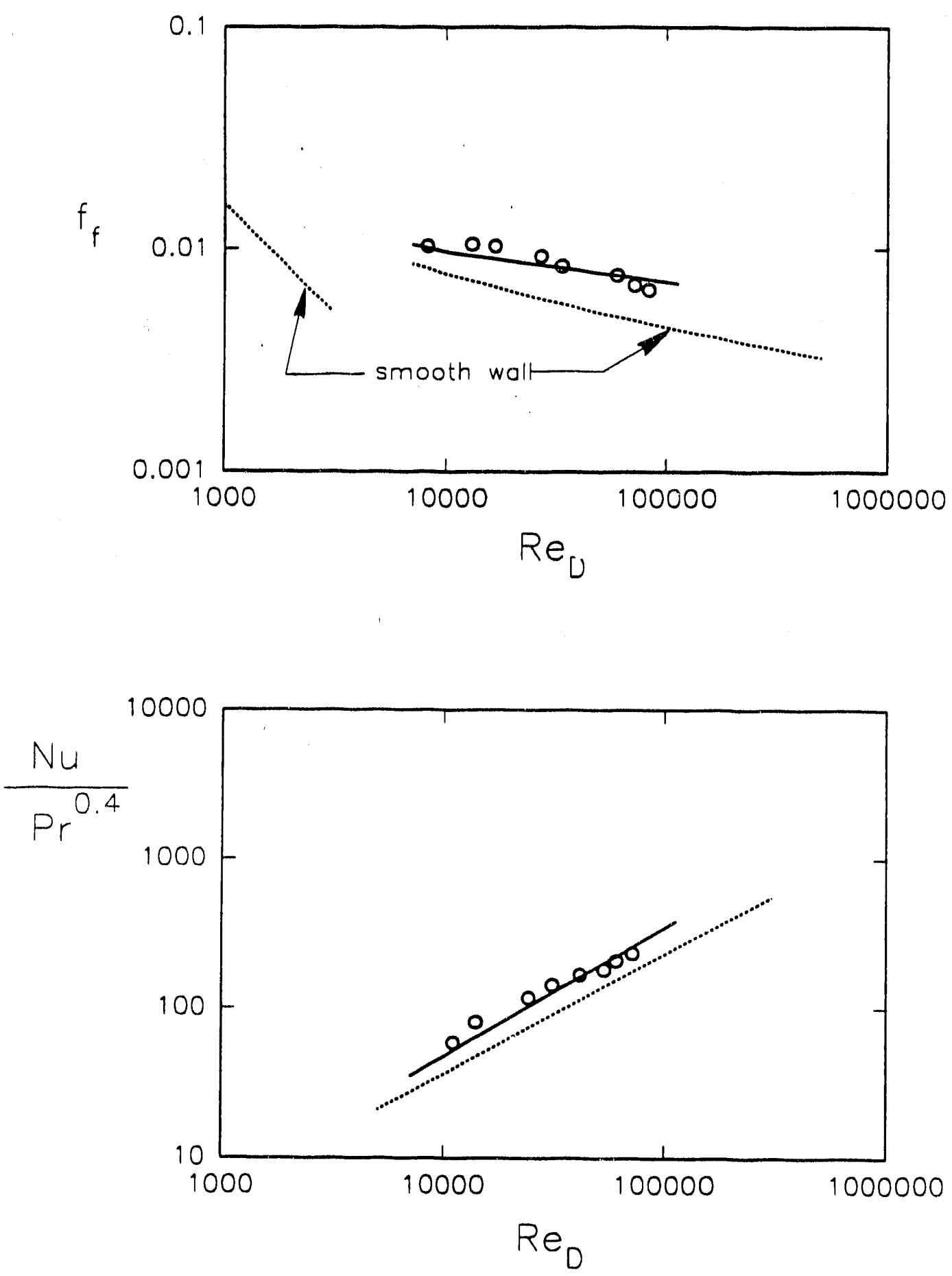

Fig. 14. Comparison of discrete element computations with the data for tube A-3 of Takahashi et al. (1985). 

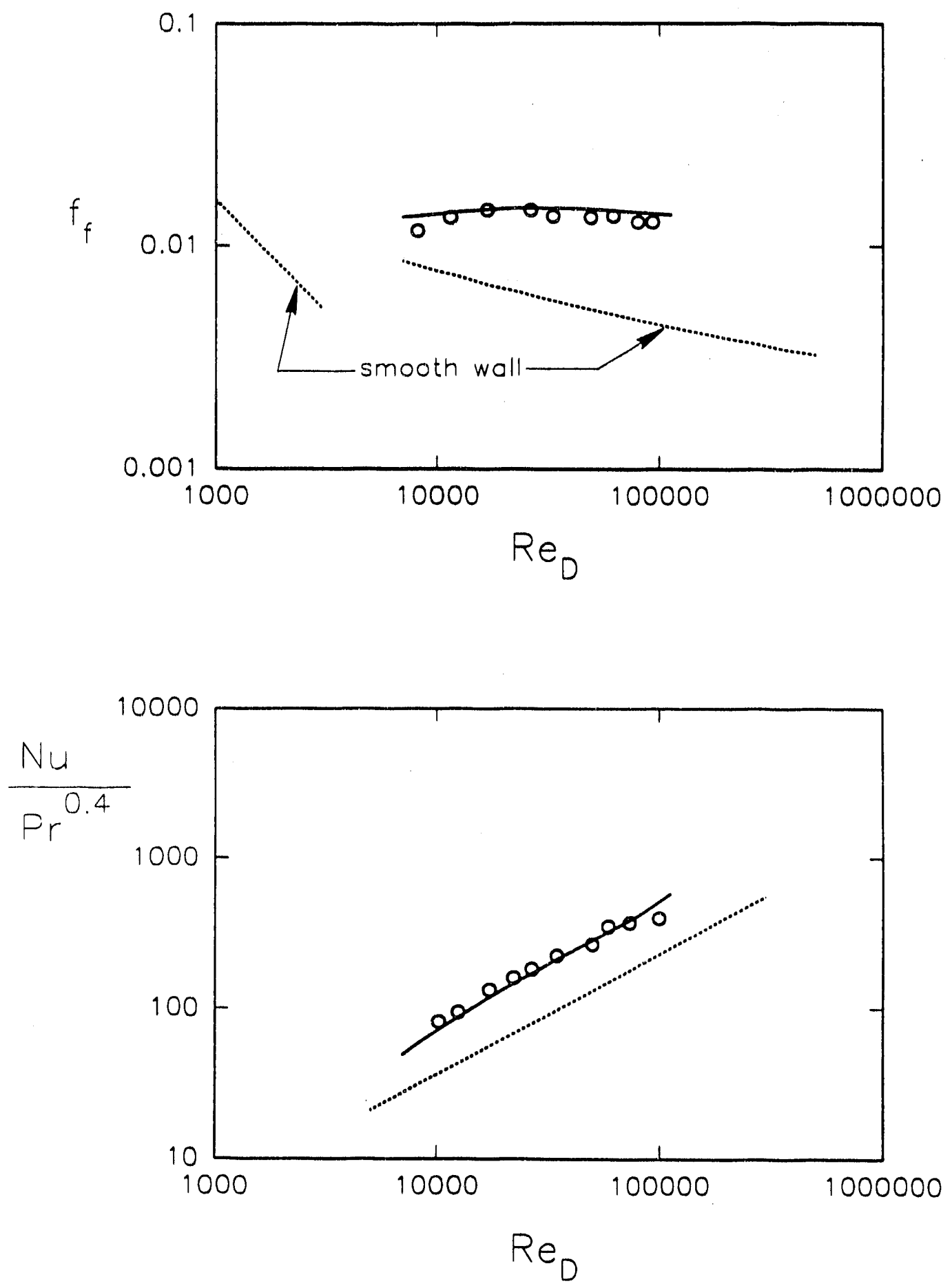

Fig. 15. Comparison of discrete element computations with the data for tube A-6 of Takahashi et ill. (1985). 

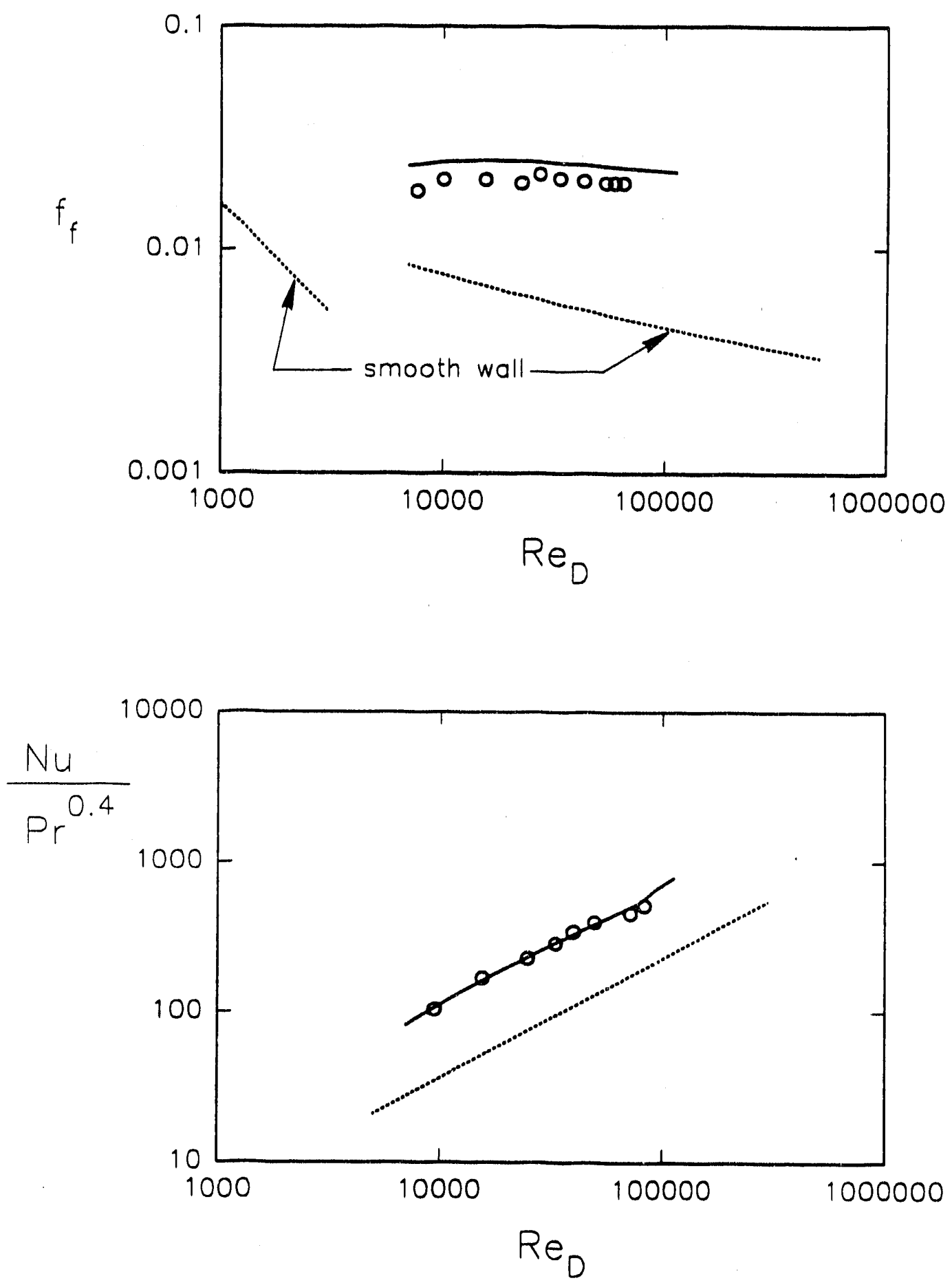

Fig. 16. Comparison of discrete element computations with the data for tube A-8 of Takahashi et al. (1985). 
Cope specified the height of his pyramids but did not specify any other dimensions. Since the photograph in Cope's paper showed the pyramids to be fairly closely spaced, the surface roughness was modeled as arrays of cones spaced two base diameters apart with the cone height equal to the pyramid height and the base diameter equal to the height. Table 5 describes the cone roughness geometry used to model these surfaces.

Figures 17-19 present the comparisons between the computations and Cope's experimental data. The friction-factor graphs in Figures 17 and 18 show excellent agreement between the predictions and the experimental data. The friction factor computations in Figure 19 exhibit a small overprediction. However, the predictions follow the trends of the data very well. Cope had considerable difficulty with the friction-factor measurements in pipe C. The solid symbols represent isothermal runs, and the open symbols represent heated runs. For pipe Reynolds numbers less than 3000 , he measured friction factors that were less than the laminar smooth wall value.

The heat transfer predictions in Figures 17-19 overpredict the Nusselt number data by a very large amount in all cases. We can give no explanation for this difference. Cope measured almost no heat transfer augmentation relative to the huge increase in pressure drop. In fact, for pipe $\mathrm{C}$ he measured a heat transfer penalty for the rough tube. Cope's almost nonexistent heat transfer augmentation is not supported by the more recent data (Dipprey and Sabersky, 1963, and Takahashi et al., 1985).

\subsection{Gowen and Smith}

Gowen and Smith (1968) reported extensive heat transfer and friction-factor measurements for tubes with the surface roughness geometry exactly specified. Their surfaces were manufactured by imprinting $0.076 \mathrm{~mm}(0.003$ in.) thick brass shimstock with a known roughness pattern. The imprinted brass sheet was cut to its final size $(41.3 \times 457 \mathrm{~mm})$ and carefully wrapped around a glass cylinder, and the seam was hard-soldered to form a tube. The manufactured tubes were placed in standard

Table 5. Geometries for the cone model of Cope's surfaces.

$\begin{array}{llllll}\text { Surface } & \begin{array}{l}\text { Pipe } \\ \text { Diameter } \\ \text { D }[\mathrm{mm}]\end{array} & \begin{array}{l}\text { Base } \\ \text { Diameter } \\ \mathrm{d}_{\mathrm{o}}[\mathrm{mm}]\end{array} & \begin{array}{l}\text { Element } \\ \text { Spacing } \\ \mathrm{L}=\ell[\mathrm{mm}]\end{array} & \begin{array}{l}\text { Element } \\ \text { Height } \\ \mathrm{k}[\mathrm{mm}]\end{array} & \begin{array}{l}\text { Projected } \\ \text { Height } \\ \mathrm{k} \text { ' }[\mathrm{mm}]\end{array} \\ \mathrm{A} & 19.7 & 1.24 & 2.48 & 1.24 & 1.24 \\ \mathrm{~B} & 19.4 & 0.66 & 1.32 & 0.66 & 0.66 \\ \mathrm{C} & 19.2 & 0.22 & 0.44 & 0.22 & 0.22\end{array}$



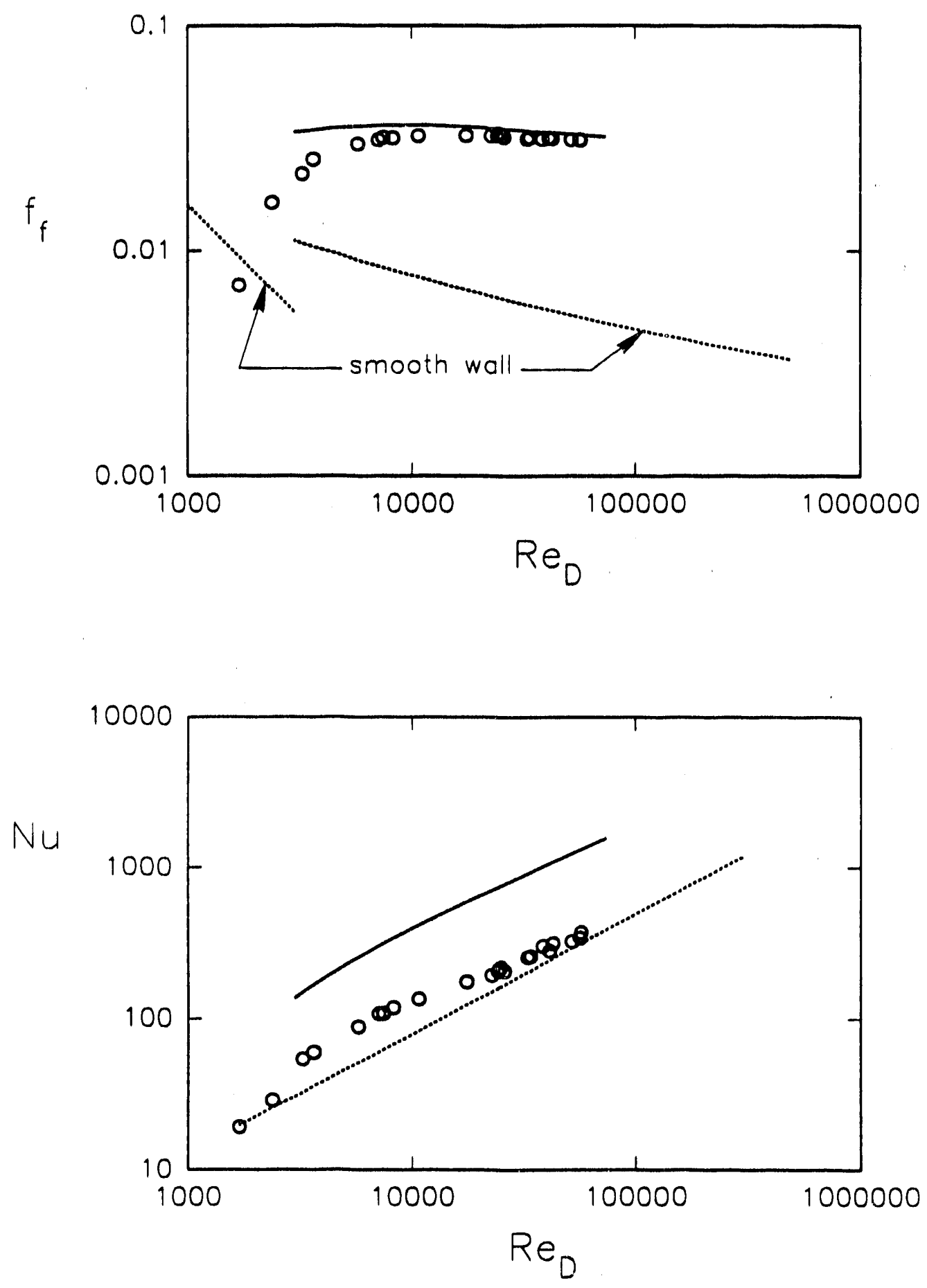

Fig. 17. Comparison of discrete element computations with the data for tube A of Cope (1941). 

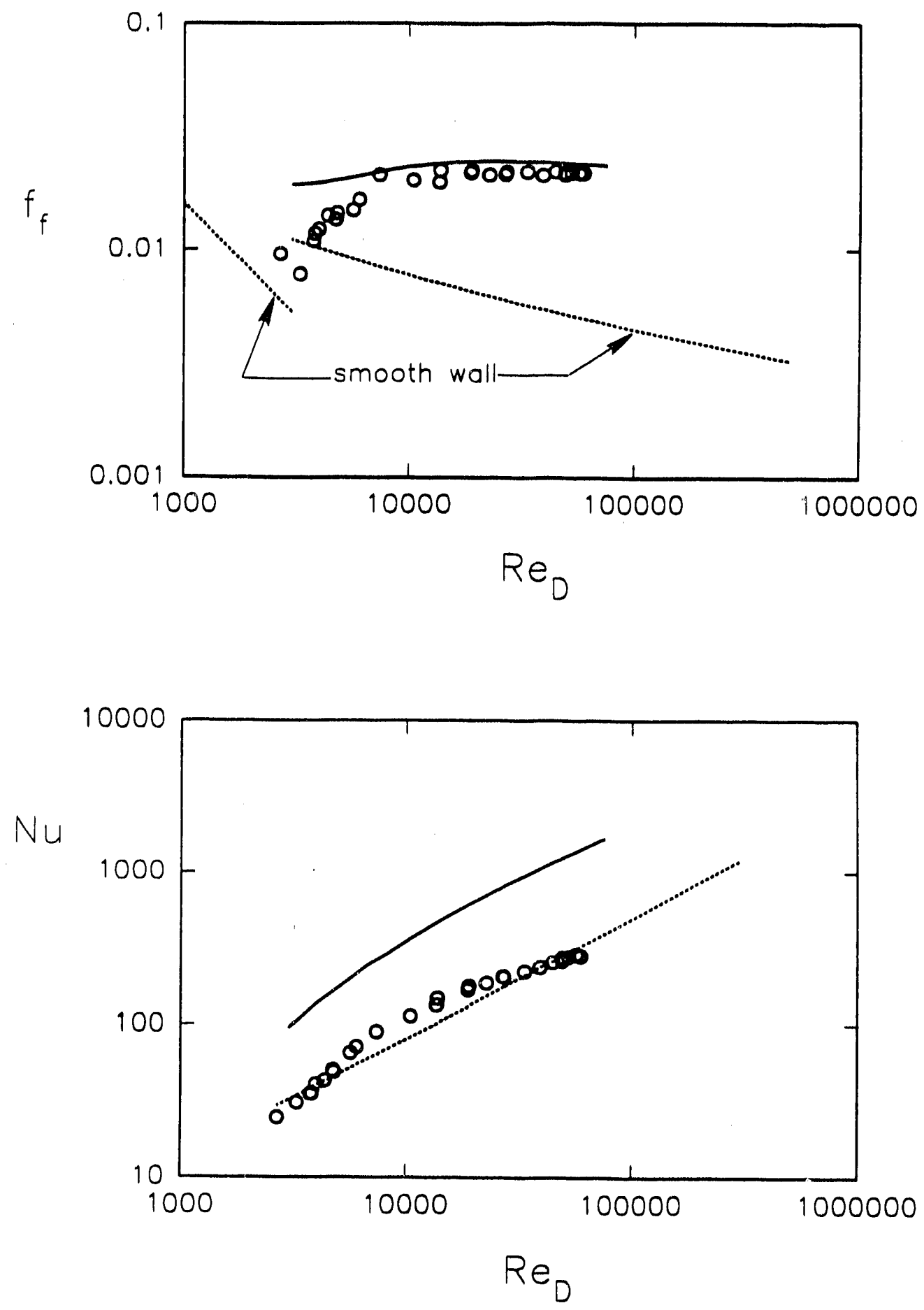

Fig. 18. Comparison of discrete element computations with the data for tube B of Cope (1941). 

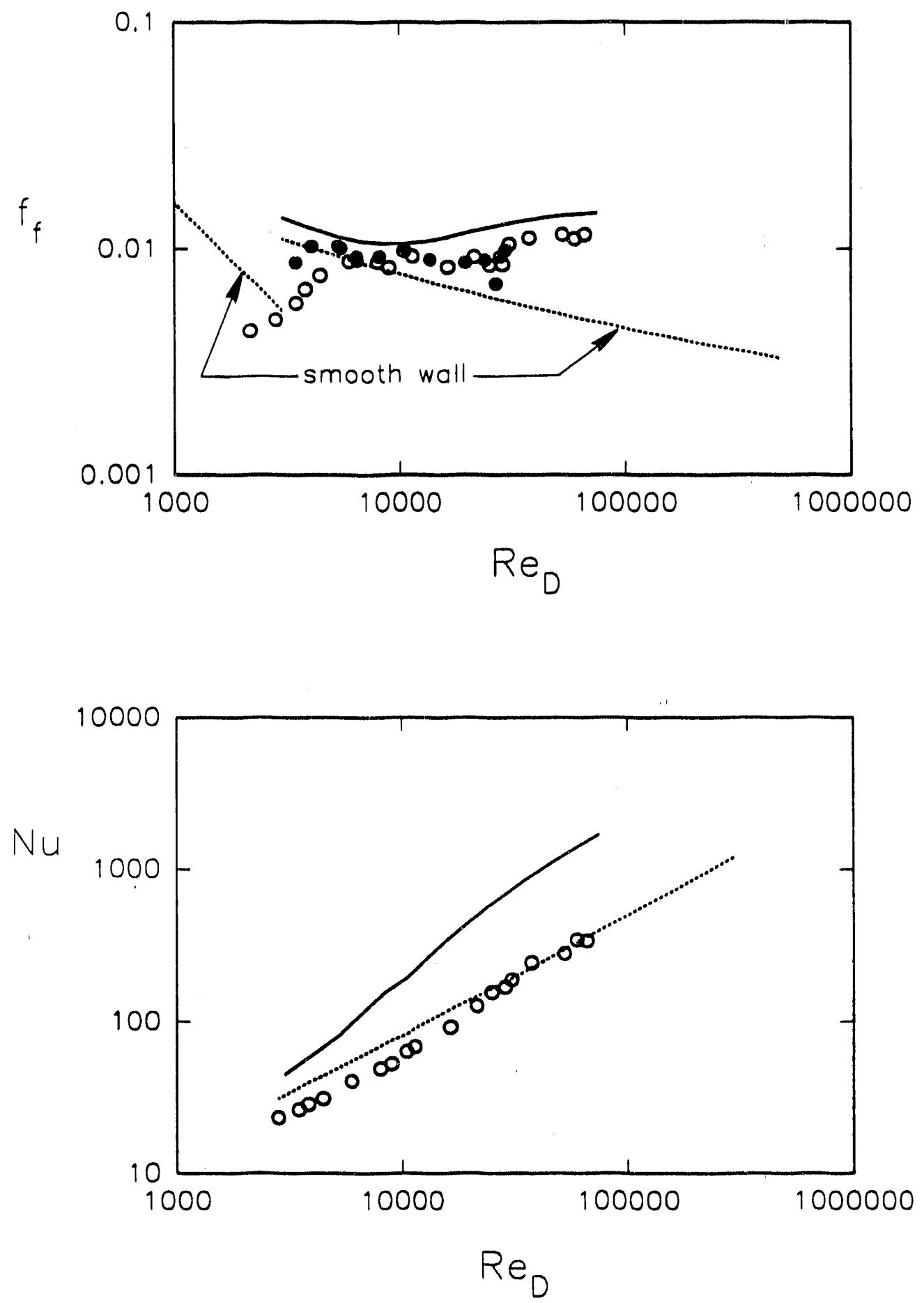

Fig. 19. Comparison of discrete element computations with the data for tube C of Cope (1941). 
one-inch $(25.4 \mathrm{~mm})$ copper tubes, and the annuli were filled with molten soft solder. When the assemblies cooled the glass cylinders were removed. Using this process the following eight different rough surfaces were manufactured: two were made with wire mesh or screen patterns, two with arrays of spherical segments, one with a random roughness pattern using carborundum particles, and three with inverted images or cavity roughness. Three of these surfaces are appropriate for comparison with the present model: the two with arrays of spherical segments and the random pattern. Unfortunately, Gowen and Smith did not report the data for the random pattern in their journal article.

The two surfaces with spherical segments were made using a pattern of 20-25 mesh copper balls $3.17 \mathrm{~mm}$ (0.125 in.) apart. We interpret the 20-25 mesh to indicate balls that will pass through a 20 mesh screen but not through a 25 mesh screen, or balls with diameters in the range $1.02 \mathrm{~mm}<\mathrm{d}^{\prime}<1.27 \mathrm{~mm}\left(0.04\right.$ in. $<\mathrm{d}^{\prime}<0.05$ in.). Gowen and Smith give the measured heights of the spherical segments to be $\mathrm{k} / \mathrm{D}=$ 0.021 and 0.025 respectively for tubes $R-2$ and R-3. Since the inside circumference was $41.3 \mathrm{~mm}$, the tube diameter was con puted to be $13.14 \mathrm{~mm}$. Figure 20 illustrates the geometry for these surfaces, and Table 6 gives their dimensions.

The heat transfer measurements were made with electrically heated pipes operating in the constant heat flux mode. The friction factors were determined using pressure drop measurements.

Figures 21 and 22 present the results of the comparison between the computations and the experimental data for these surfaces. Inspection of the figures reveals that the computations significantly underpredict (20-30\%) the data for the friction factor. Gowen and Smith provided heat transfer results for three different fluids: $\operatorname{air}(\operatorname{Pr}=0.7)$, water $(\operatorname{Pr}=6.0)$, and ethylene glycol $(\operatorname{Pr}=15.5)$. The Nusselt number plots show the comparisons for $\operatorname{Pr}=0.7$ and $\operatorname{Pr}=15.5$. For $\operatorname{Pr}=0.7$, the predictions are below the data by a significant amount. For $\operatorname{Pr}=15.5$, the predictions and the data are in good agreement. The cases for water $(\operatorname{Pr}=6.6)$ exhibit similar agreement to that for $\operatorname{Pr}=15.5$.

Table 6. Dimensions for the spherical segment surfaces of Gowen and Smith.

$\begin{array}{llllll}\text { Surface } & \begin{array}{l}\text { Pipe } \\ \text { Diameter } \\ \text { D [mm] }\end{array} & \begin{array}{l}\text { Base } \\ \text { Diameter } \\ d_{0}[\mathrm{~mm}]\end{array} & \begin{array}{l}\text { Element } \\ \text { Spacing } \\ \mathrm{L}=\ell[\mathrm{mm}]\end{array} & \begin{array}{l}\text { Element } \\ \text { Height } \\ \mathrm{k}[\mathrm{mm}]\end{array} & \begin{array}{l}\text { Projected } \\ \text { Height } \\ k^{\prime}[\mathrm{mm}]\end{array} \\ \text { R-2 } & 13.14 & 1.06 & 3.17 & 0.277 & -- \\ \text { R-3 } & 13.14 & 1.20 & 3.17 & 0.328 & --\end{array}$




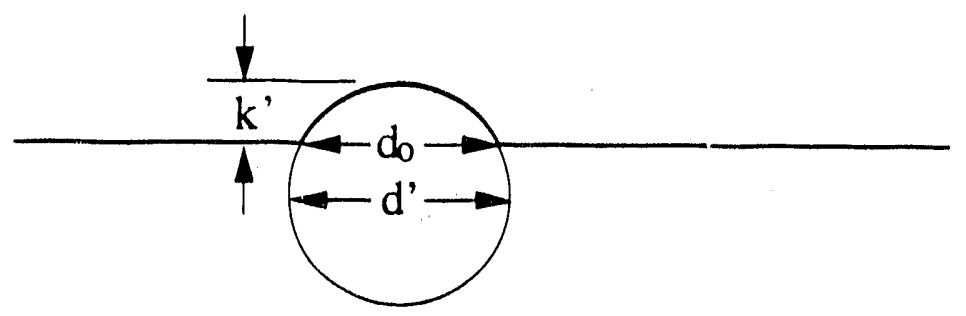

Fig. 20. Diagram illustrating the manufacture of roughness by Gowen and Smith (1968).

Gowen and Smith's data indicate the heat transfer augmentation to be greater for $\operatorname{Pr}=0.7$ than for $\operatorname{Pr}=15.5$. This is not in agreement with the other data (Dipprey and Sabersky, for example). For large Prandtl numbers, the thermal resistance is more dependent on the sublayer, and we would expect roughness to have a greater effect on the heat transfer.

\subsection{Omitted Test Cases}

In the original plans for this research project, data from experiments in progress by Obot were to be used as validation cases. Unfortunately, these data were not available during the course of this work and, therefore, the comparisons could not be performed.

Also, the geometries tested by Dawson and Trass (1972) were to be used as validation cases. They measured mass transfer in a square channel where one side was rough and the remaining three sides were smooth. The roughness model used herein could be applied to this situation; however, a square duct with one rough wall would require a solution of the parabolized Navier-Stokes equations with the roughness model. Such an effort is beyond the scope of this project.

Of the eleven surfaces tested by Takahashi et al. (1985), eight were omitted because these roughness geometries contained significant two-dimensional rib characteristics. Before the model can be applied to this type of surface, considerable development of the discrete element method is required to include the combined effects of two and three-dimensional roughness as well as swirl.

Of the eight geometries tested by Gowen and Smith (1968), six were omitted. One was omitted because the data for that case were not presented in the article. The others were omitted because the nature of the roughness was more akin to cavities than to protrusions. The present development of the discrete element model is based 

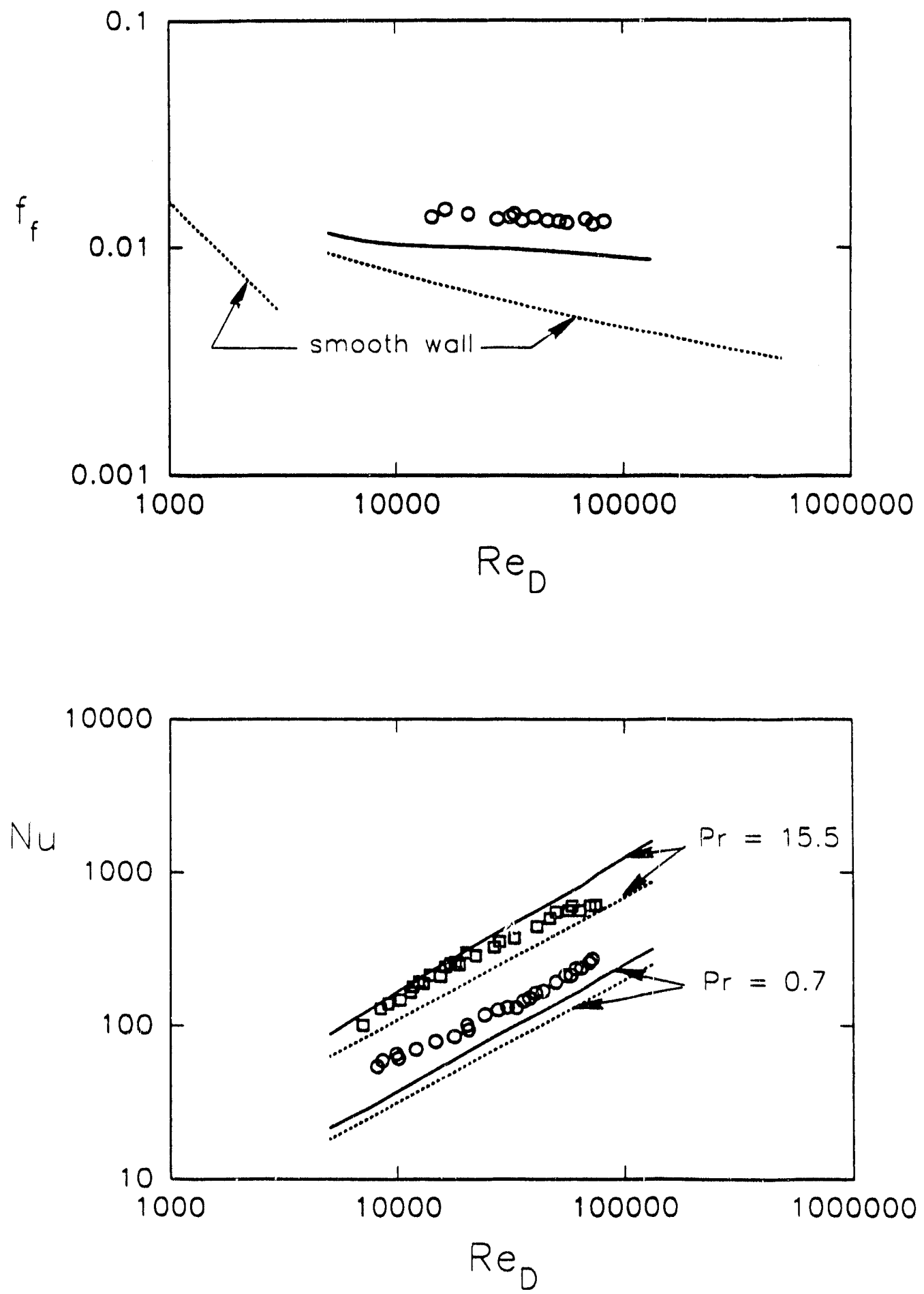

Fig. 21. Domparison of discrete element computations with the data fo: tube R-2 of Gowen and Smith (1968). 

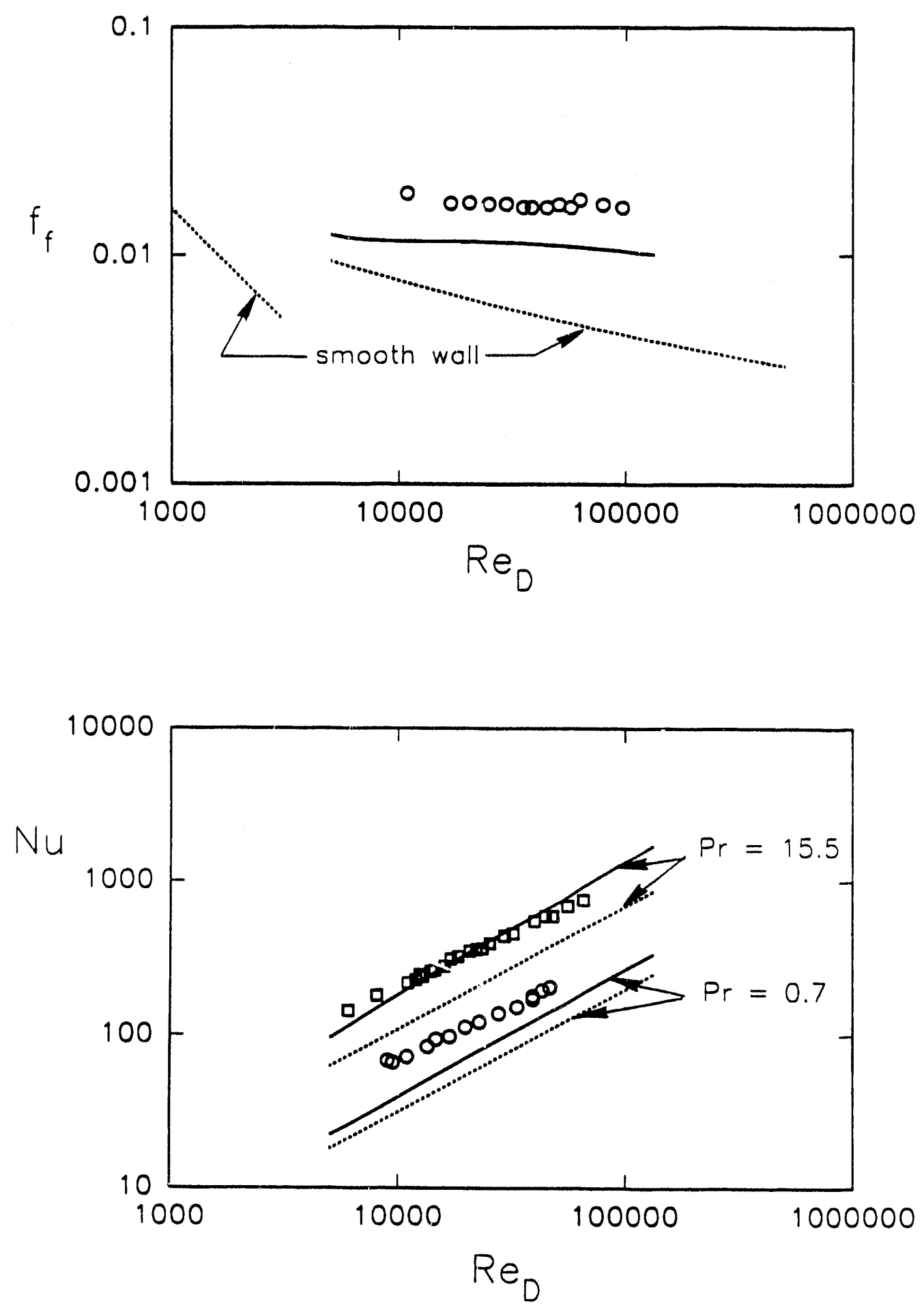

Fig. 22. Comparison of discrete element computations with the data for tube R-3 of Gowen and Smith (1968). 
on the assumption that the roughness elements are protrusions. The model could be expanded to account for cavities; however, this would take a significant development effort and would most likely require additional experiments. 


\section{SECTION V}

\section{SUMMARY AND RECOMMENDATIONS}

A discrete element prediction method has been developed and validated for fully developed flow and heat transfer in a circular pipe with uniformly distributed three-dimensional surface roughness. This model has been shown to be consistent with the usual concepts of thermally developed flow.

Comparisons with experimental data from the literature were very good overall. The comparisons with the data of Dipprey and Sabersky (1963) and Takahashi et al. (1985) were excellent. The friction factor predictions were in excellent agreement with the data of Cope (1941); however, the heat transfer computations considerably overpredicted the data. Cope's experiments indicated a very small heat transfer augmentation compared to the massive skin friction augmentation, which is not consistent with the more recent experiments. We consider Cope's heat transfer data to be pathological. The agreement with the data of Gowen and Smith (1968) was fair. The friction factor computations underpredicted the data by $20-30 \%$, and the heat transfer agreement ranged from good to fair depending on Prandtl number. Gowen and Smith's roughness elements were low, broad spherical segments $\left(d_{o} / k \approx 4-5\right)$. The present model was calibrated using more upstanding elements such as hemispheres and cones. Also, their heat transfer data was inconsistent with the other experiments, showing the greatest heat transfer augmentation for the lowest Prandtl number tested.

We recommend that the present prediction method be refined and extended to other roughness forms such as: 1) two-dimensional rib roughness, 2) threedimensional roughness elements of noncircular cross section, and 3) three-dimensional dimple or cavity roughness.

The authors and their colleagues have presented some work with the discrete element method for friction factor predictions with two-dimensional rib roughness (Taylor et al., 1989). The extension to heat transfer predictions is conceptually straightforward. Repeated rib roughness can be modeled using solutions to the Reynolds averaged Navie:-Stokes equations. Using such solutions to predict the flow and thermal details along with the extensive experimental data base for rib roughness would be sufficient for the calibration of this model. No additional experiments should be needed.

In the course of the present project, noncircular roughness elements were modeled with some sort of equivalent element. This approach was very successful; however, it did require some limited numerical experiments. We recommend that a more systematic study be undertaken to set up a means to account for elements with 
noncircular cross section. The present experimental data should be sufficient for a first look at this problem.

Dipprey and Sabersky proposed a cavity flow model for heat transfer with a rough surface. Conceptually, their model is very similar to the present discrete element model which considers bumps. They defined a local cavity Nusselt number which was proportional to powers of a local cavity Reynolds number and the Prandtl number:

$$
N u_{\text {covity }} \sim R e_{\text {cavity }}^{a} \operatorname{Pr}^{b}
$$

The integration of such a model into the discrete element solution procedure is conceptually straightforward. Some experimental heat transfer data with dimple roughness are available. However, detailed Navier-Stokes solutions and additional experiments would most likely be required to calibrate the model. 


\section{REFERENCES}

J. C. Adams and B. K. Hodge, 1977, The calculation of compressible transitional turbulent and relaminarizational boundary layers over smooth and rough surfaces using an extended mixing-length hypothesis, AlAA Paper 77-682.

G. H. Christoph, 1982, Law of the wall analysis for turbulent heating on rough surfaces, AIAA Paper 82-0197.

G. H. Christoph and R. N. Pletcher, 1983, Prediction of rough-wall skin friction and heat transfer, AlAA J., 21, 4, 509-515.

W. G. Cope, 1945, The friction and heat transmission coefficients of rough pipes, Proc. of the Institute of Mechanical Engineers, London, 145, 99-105.

D. W. Dawson and O. Trass, 1972, Mass transfer at rough surfaces, Intermational J. Heat Mass Transfer, 15, 1317-1336.

D. F. Dipprey and R. H. Sabersky, 1963, Heat and momentum transfer in smooth and rough tubes at various Prandtl numbers, International J. Heat Mass Transfer, 6, 329353.

M. L. Finson, 1975, A Reynolds stress model for boundary layer transition with applications to rough surfaces, AFOSR-TR-76-0322.

M. L. Finson and P. K. S. Wu, 1979, Analysis of rough wall turbulent heating with applications to blunted flight vehicles, AIAA Paper 79-008.

M. L. Finson and A. S. Clark, 1980, The effects of surface roughness character on turbulent reentry heating, AIAA Paper 80-1459.

M. L. Finson, 1982, A model for rough wall turbulent heating and skin friction, AIAA Paper 82-0199.

R. A. Gowen and J. W. Smith, 1968, Turbulent heat transfer from smooth and rough surfaces, International J. Heat Mass Transfer, 11, 1657-1673.

M. H. Hosni, H. W. Coleman, and R. P. Taylor, 1989, Measurement and calculation of surface roughness effects on turbulent flow and heat transfer, Report TFD-89-1, Mech. and Nuc. Engr. Dept., Miss. State Univ. 
M. H. Hosni, H. W. Coleman, and R. P. Taylor, 1991, Measurements and calculations of rough-wall heat transfer in the turbulent boundary layer, International J. Heat Mass Transfer, 34, 4/5, 1067-1081.

W. M. Kays and M. E. Crawford, 1980, Convective Heat and Mass Transfer, 2nd ed., McGraw-Hill, New York, NY.

T. C. Lin and R. J. Bywater, 1980, The evaluation of selected turbulence models for high-speed rough wall boundary layer calculations, AIAA Paper 80-0132.

W. F. Scaggs, R. P. Taylor, and H. W. Coleman, 1988a, Measurement and prediction of rough wall effects on friction factor--uniform roughness results, J. Fluids Engr., $110,385-391$.

W. F. Scaggs, R. P. Taylor, and H. W. Coleman, 1988b, Measurement and prediction of rough wall effects on friction factors in turbulent pipe flow, Report TFD-88-1, Mech. and Nuc. Engr. Dept, Miss. State Univ.

H. Schlichting, 1936, Experimentelle untersuchungen zum rauhigkeits-problem, Ingenieur-Archive., VII, 1, 1-34.

K. Takahashi, W. Nakayama, and H. Kuwahara, 1985, Enhancement of forced convective heat transfer in tubes having three-dimensional spiral ribs, Trans. JSME, $51-461,350-355$.

R. P. Taylor, H. W. Coleman, and B. K. Hodge, 1984, A discrete element prediction approach for turbulent tlow over rough surfaces, Report TFD-84-1, Mech. and Nuc. Engr. Dept., Miss. State Univ.

R. P. Taylor, H. W. Coleman, and B. K. Hodge, 1985, Prediction of turbulent roughwall skin friction using a discrete element approach, J. Fluids Engr., 107, 251-257.

R. P. Taylor, W. F. Scaggs, and H. W. Coleman, 1988, Measurement and prediction of nonuniform surface roughness on turbulent flow friction coefficients, J. Fluids Engr. $110,380-384$.

R. P. Taylor, B. K. Hodge, and H. W. Coleman, 1989, A discrete element model for turbulent skin friction prediction for rib-type surface roughness, Int. J. Heat and Technology, Vol. 7, No. 1, pp 29-48. 


\section{APPENDIX I}

\section{THE IMPLICIT FINITE DIFFERENCE METHOD}

The equations are written in the general form

$$
w^{\prime \prime}+\gamma_{1} w^{\prime}+\gamma_{2} w+\gamma_{3}=0
$$

where $w=\tilde{u}$ for the momentum equation and $w=\tilde{\theta}$ for the energy equation. The prime indicates differentiation with respect to $\eta=\tilde{y}$.

The derivatives in equation (I-1) are approximated by finite difference formulas in the grid network shown in Figure I-1. A geometrically expanding grid is used in the $\eta$-direction. The expanding grid is given by the recursion formula

$$
\left.\Delta \eta\right|_{n}=R(\Delta \eta)_{n-1}
$$

where $R$ is a constant (taken herein as $R=1.063$ ). The first $\eta$-step, $\left.\Delta \eta\right|_{1}$, must be specified and is taken here as $\left.\Delta \eta\right|_{1}=0.701 \times 10^{-5}$. The expanding $\eta$-grid is chosen because it concentrates the points near the surface where the gradients are the steepest. With $R=1.063,\left.\Delta \eta\right|_{1}=0.701 \times 10^{-5}$, and $\mathrm{N}=150$, the largest $\eta$ value is unity, forcing 150 points to exactly fit in the pipe radius. On a typical run about half of the $\eta$-points are in the lower $5-10 \%$ of the boundary layer.

The derivatives with respect to $\eta$ are approximated by using a three-point Lagrangian interpolation formula. The dependent variable $w$ is approximated in the range $\eta_{n-1} \leq \eta \leq \eta_{n+1}$ by a Lagrangian polynomial

$$
w(\eta)=\sum_{1=n-1}^{n+1} L_{i} w_{i}+E
$$




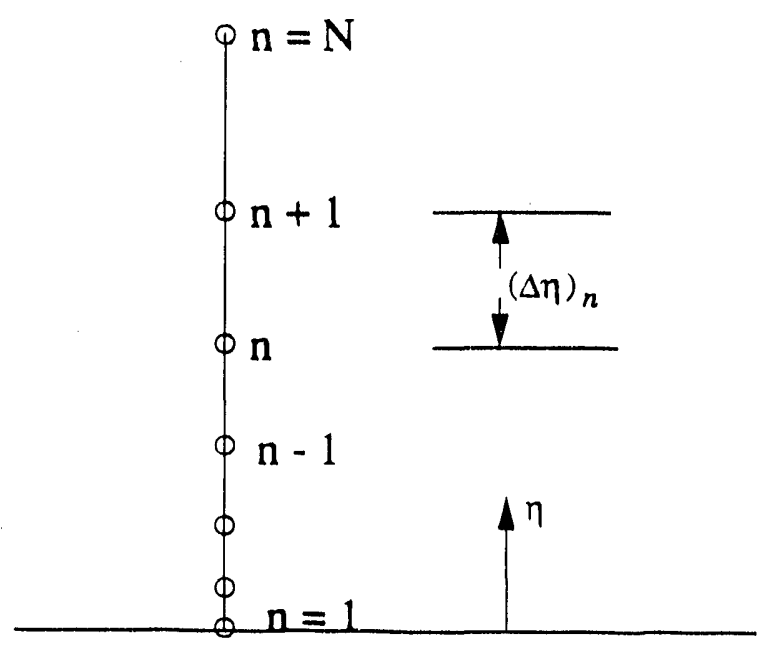

Fig. I.1. Layout of the expanding finite difference grid.

where

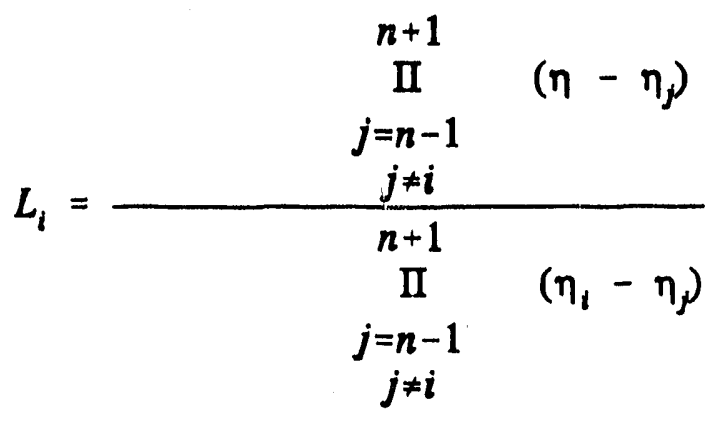

Taking the first and second derivatives of equation (I-3) and evaluating at $\eta=\eta_{n}$ yields the finite difference formulae

$$
\begin{aligned}
& \left.\frac{\partial^{2} w}{\partial \eta^{2}}\right|_{n}=\frac{2\left[w_{n+1}+R w_{n-1}-(1+R) w_{n}\right]}{(\Delta \eta)_{n}^{2}+R(\Delta \eta)_{n-1}^{2}}+E^{\prime \prime} \\
& \left.\frac{\partial w}{\partial \eta}\right|_{n}=\frac{\left[w_{n+1}-R^{2} w_{n-1}-\left(1-R^{2}\right) w_{n}\right]}{(\Delta \eta)_{n}+R^{2}(\Delta \eta)_{n-1}}+E^{\prime}
\end{aligned}
$$


where

$$
\left.\Delta \eta\right|_{n}=\eta_{n+1}-\eta_{n}
$$

The errors can be shown to be $E^{\prime}=-(1 / 6) w^{\prime \prime \prime}(\Delta \eta)_{n}(\Delta \eta)_{n-1}$ and $E^{\prime \prime}=$ $-(1 / 12) w^{\prime \prime \prime \prime}(\Delta \eta)_{n}(\Delta \eta)_{n+1}$. From this we see the usefulness of the expanding grid. Near the wall, where the derivatives are large, small values of $\Delta \eta$ are required to keep truncation errors small. Far from the wall, the derivatives are small, and larger $\Delta \eta$ 's are acceptable.

Substituting and rearranging yields a system of $\mathrm{N}-2$ algebraic equations

$$
A_{n} w_{n-1}+B_{n} w_{n}+C_{n} w_{n+1}=D_{n}
$$

where

$$
n=2,3, \ldots ., N-1
$$

The coefficients A, B, C and D are given by

$$
\begin{gathered}
A_{n}=\frac{2 R}{S_{1}}-\frac{R^{2} \gamma_{1}}{S_{2}} \\
B_{n}=-\frac{2(1+R)}{S_{1}}-\frac{\gamma_{1}\left(1-R^{2}\right)}{S_{2}}+\gamma_{2} \\
C_{n}=\frac{2}{S_{1}}+\frac{\gamma_{1}}{S_{2}} \\
D_{n}=-\gamma_{3}
\end{gathered}
$$

where

$$
S_{1}=(\Delta \eta)_{n}^{2}+R(\Delta \eta)_{n-1}^{2} \text { and } S_{2}=(\Delta \eta)_{n}+R^{2}(\Delta \eta)_{n-1} \text {. }
$$


The $N$ - 2 equations are linear if the terms $A_{n}, B_{n}, C_{n}$, and $D_{n}$ are taken to be constants at a station $\mathrm{n}$. This is the case for the energy equations, (60) and (70), and for the laminar version of the momentum equation for smooth pipes (49). The resulting set of algebraic equations can be solved directly as discussed below. For turbulent flow, the momentum equation is nonlinear because the eddy viscosity depends on the velocity profile, and, for rough-wall flows, the drag force term contains $\tilde{u} \cdot \tilde{u}$. To overcome this problem, the following linearization procedure is adopted. The velocity profile is initially assumed to be the $1 / 7$-power law. The eddy viscosity and the first $\tilde{u}$ in the drag term are determined based on this profile. The resulting linear set of equations is solved for a second approximation to $\tilde{u}$. These approximations are used to obtain new approximations in an iterative manner until the difference between successive iterations is less than a preset value.

The equations that result from an expansion of (I-7) are shown in Figure I-2a. The value $w_{1}$ is always specified, $w_{1}=0$, based on the wall boundary condition for the particular equation. However, the value $w_{N}$ is not known, and equations (I-7) result in $\mathrm{N}-2$ equation and $\mathrm{N}-1$ unknowns. The additional equation is provided by the boundary condition

$$
\left.\frac{\partial w}{\partial \eta}\right|_{N}=\frac{R^{2} w_{N-2}-\left[R^{2}+2 R+1\right] w_{N-1}+(2 R+1) w_{N}}{(\Delta \eta)_{N}+R^{2}(\Delta \eta)_{N-1}}=0
$$

Solving for $w_{N}$ gives

$$
w_{N}+\frac{(R+1)^{2}}{2 R+1} w_{N-1}-\frac{R^{2}}{2 R+1} w_{N-2}
$$

These equations are readily transformed into Jordan canonical form, Figure I-2b, by the relations

$$
\begin{gathered}
\lambda_{2}=\frac{B_{2}}{C_{2}} \\
E_{2}=\frac{\left(D_{2}-A_{2} w_{1}\right)}{C_{2}}
\end{gathered}
$$




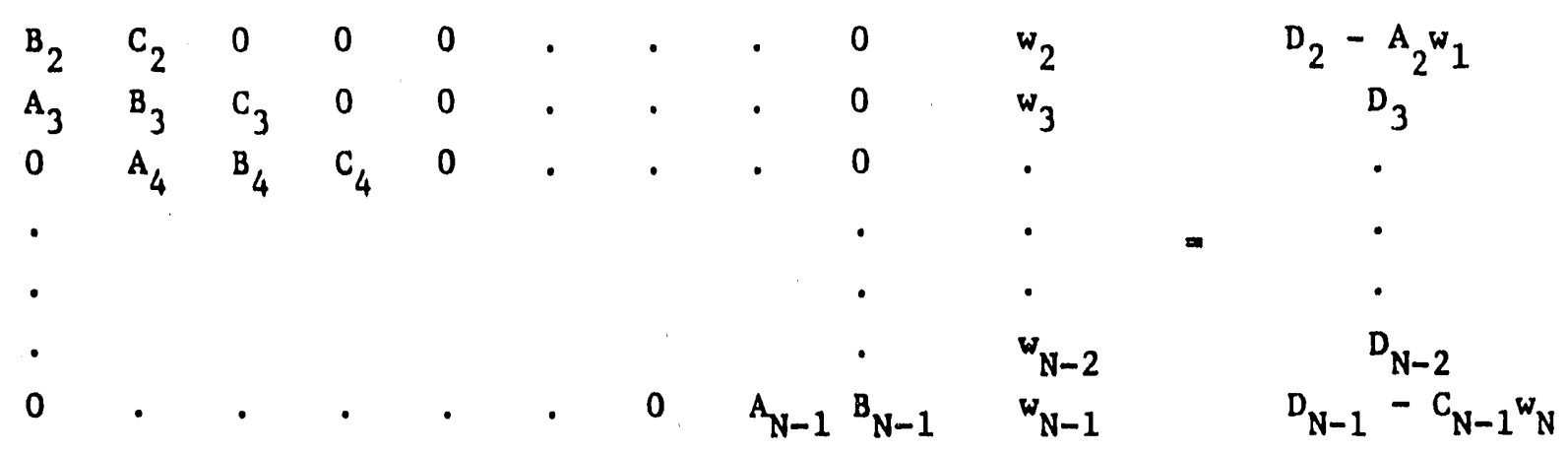

(a)

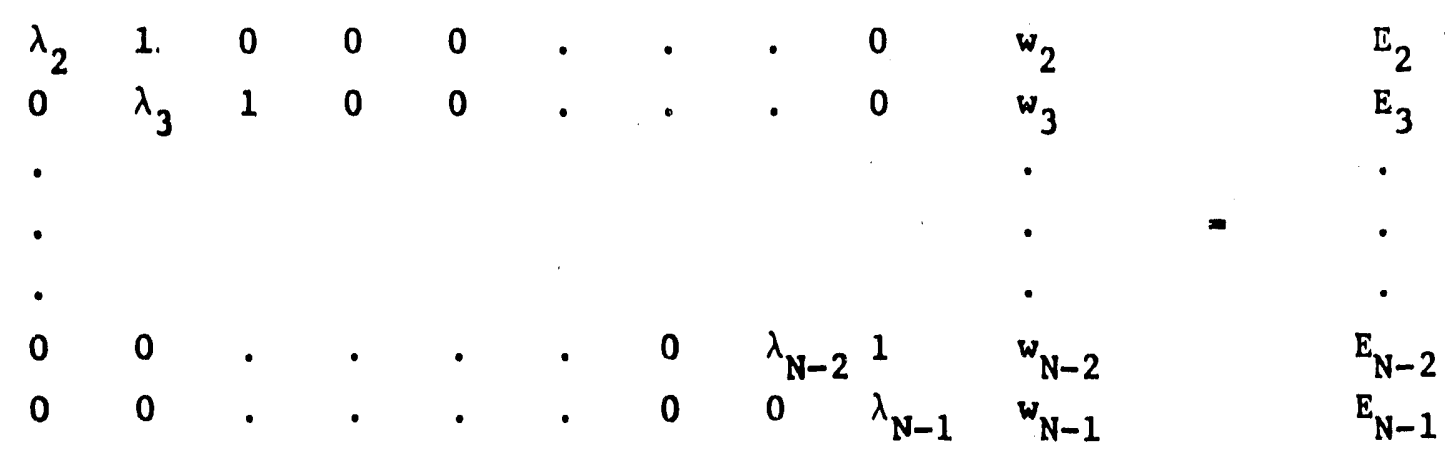

(b)

Fig. I-2. Matrix from linearized equations: a) tridiagonal form; b) canonical form.

$$
\begin{array}{ll}
\lambda_{n}=\frac{B_{n}}{C_{n}}-\frac{A_{n}}{\left(C_{n} \lambda_{n-1}\right)} & n=3, N-2 \\
E_{n}=\frac{D_{n}}{C_{n}}-\frac{\left(A_{n} E_{n-1}\right)}{\left(C_{n} \lambda_{n-1}\right)} & n=3, N-2
\end{array}
$$




$$
\begin{gathered}
\lambda_{N-1}=B_{N-1}+C_{N-1} \frac{(R+1)^{2}}{2 R+1}-\frac{\left(A_{N-1}-C_{N-1} \frac{R^{2}}{2 R+1}\right)}{\lambda_{N-2}} \\
E_{N-1}=D_{N-1}-\frac{\left(A_{N-1}-C_{N-1} \frac{R^{2}}{2 R+1}\right) E_{N-2}}{\lambda_{N-2}}
\end{gathered}
$$

The canonical form is easily solved for the $w_{n}$ 's by starting at station $N-1$

$$
w_{N-1}=\frac{E_{N-1}}{\lambda_{N-1}}
$$

and back-substituting

$$
w_{n}=\frac{E_{n}}{\lambda_{n}}-\frac{W_{n+1}}{\lambda_{n}} \quad n=N-2, N-3, \ldots .2
$$




\section{APPENDIX II}

\section{THE COMPUTER CODES}

This appendix gives the listings for the FORTRAN codes which form the computer program. All sections of this program are nondimensional except the INPUT subroutine. All variables are nondimensionalized in INPUT before they are passed out of the subroutine. Throughout the code attempts were made to use variable names which were close facsimiles of the symbols in the mathematical development in the text.

The programs and subroutines are listed in the following order.

\section{Page}

II-1. Program PIPE . . . . . . . . . 59 59

II-2. Subroutine INPUT $\ldots \ldots \ldots \ldots \ldots 60$

II-3. Subroutine GRID . . . . . . . . 61

II-4. Subroutine ROUGH . . . . . . . . 6 61

II-5. Subroutine FANING . . . . . . . 62

II-6. Subroutine NUSLTH $\ldots \ldots \ldots \ldots 64$

II-7. Subroutine NUSLTT . . . . . . . 65

II-8. Subroutine FLOW . . . . . . . . . 66

II-9. Subroutine CONSTH $\ldots \ldots \ldots \ldots 67$

II-10. Subroutine CONSTT . . . . . . . 67

II-11. Real Function umean . . . . . . . 68

II-12. Real Function tmean . . . . . . . . 68

II-13. Subroutine PRINT $\ldots \ldots \ldots \ldots \ldots 6$

II-14. Subroutine EDDY $\ldots \ldots \ldots \ldots \ldots 70$

II-15. Subroutine EDDY2 . . . . . . . . 71

II-16. Subroutine ABCDF $\ldots \ldots \ldots \ldots 72$

II-17. Subroutine ABCDH $\ldots \ldots \ldots \ldots 73$

II-18. Subroutine ABCDT $\ldots \ldots \ldots \ldots .74$

II-19. Subroutine SOLVE $\ldots \ldots \ldots \ldots \ldots 75$

II-20. Subroutine DRAG . . . . . . . . 76

II-21. Subroutine HEAT . . . . . . . . . 76

The programs were developed using Microsoft. FORTRAN 5.0 on a personal computer running the MS-DCS operating system. The lines \$DECLARE and \$STRICT are Microsoft FORTRAN commands that forced the compiler to obey strict FORTRAN 77 standards, thereby easing portability to other environments. The program has been successfully ported to the SUN SPARC environment with no changes other than the removal of the $\$$ commands. 
The subroutine FANING computes the Fanning friction factor and velocity profile. It requires input from the subroutines INPUT, GRID, and ROUGH. The subroutine NUSLTH computes the Nusselt number and temperature profile for the constant wall heat flux boundary condition. It requires the velocity profile and eddy viscosity profile from FANING. Likewise, NUSLTT corresponds to the constant wall temperature boundary condition.

\section{- NOTICE -}

Electronic copies of the computer codes presented in this appendix are available from:

Energy Science and Technology Software Center P.O. Box 1020

Oak Ridge, Tennessee 37831-1020

For information regarding requests for software, call (615) 576-2606. 
SDECLARE

\$STRICT

Program PIPE

Real RED, cd, do, k, kprime, cl, sl,piprad,y (150), d (150), BETA (150)

Real ff, u (150), aumean, Lstar (150)

Real Nud, ThetaH (150), ThetaT (150), Pr, PrT, NuH, NuT, tmeanT, tmeanH

Integer Npts

call INPUT (RED, cd, Nud, do , k, kprime, cl, sl, piprad, Pr, PrT)

call GRID (Npts,Y)

cal1 ROUGH (Npts, do, k, kprime, y, cl, sl, d, BETA)

call FANING (Npts, RED, cd, d, cl, sl,y, BETA, ff, u, aunean, Lstar) write $(*, *)$ RED, ff

call NUSLTH (Npts, $y, u$, ThetaH, RED, Pr, PrT, BETA, Nud, $d, c 1, s 1$, 1 Lstar, Nuh, trieanH)

write $(*, *)$ 'Constant Heat Flux', NuH

cal1 NUSLTT (Npts, $y, u$, ThetaT, RED, Pr, PrT, BETA, NuT, Nud, d, cl, sl, 1 tmeanT, Lstar)

write $(*, *)$ 'Constant Temperature', NuT

cal1 PRINT (Npts, Y, u, BETA, d, RED, piprad, d0, k, kprime,

1

cl, sl, ff, aumean, ThetaH, ThetaT, iNuH, NuT,

2

tmeanH, tmeanT)

Stop

End 
Subroutine INPUT (RED, cd, Nud, do,k, kprime, cl,sl, piprad, Pr, PrT)

Real RED, cd, Nud, do, k, kprime, cl, sl, piprad, Pr, PrT

C Enter the Pipe Reynolds number and the relative roughness C normalized by the pipe radius

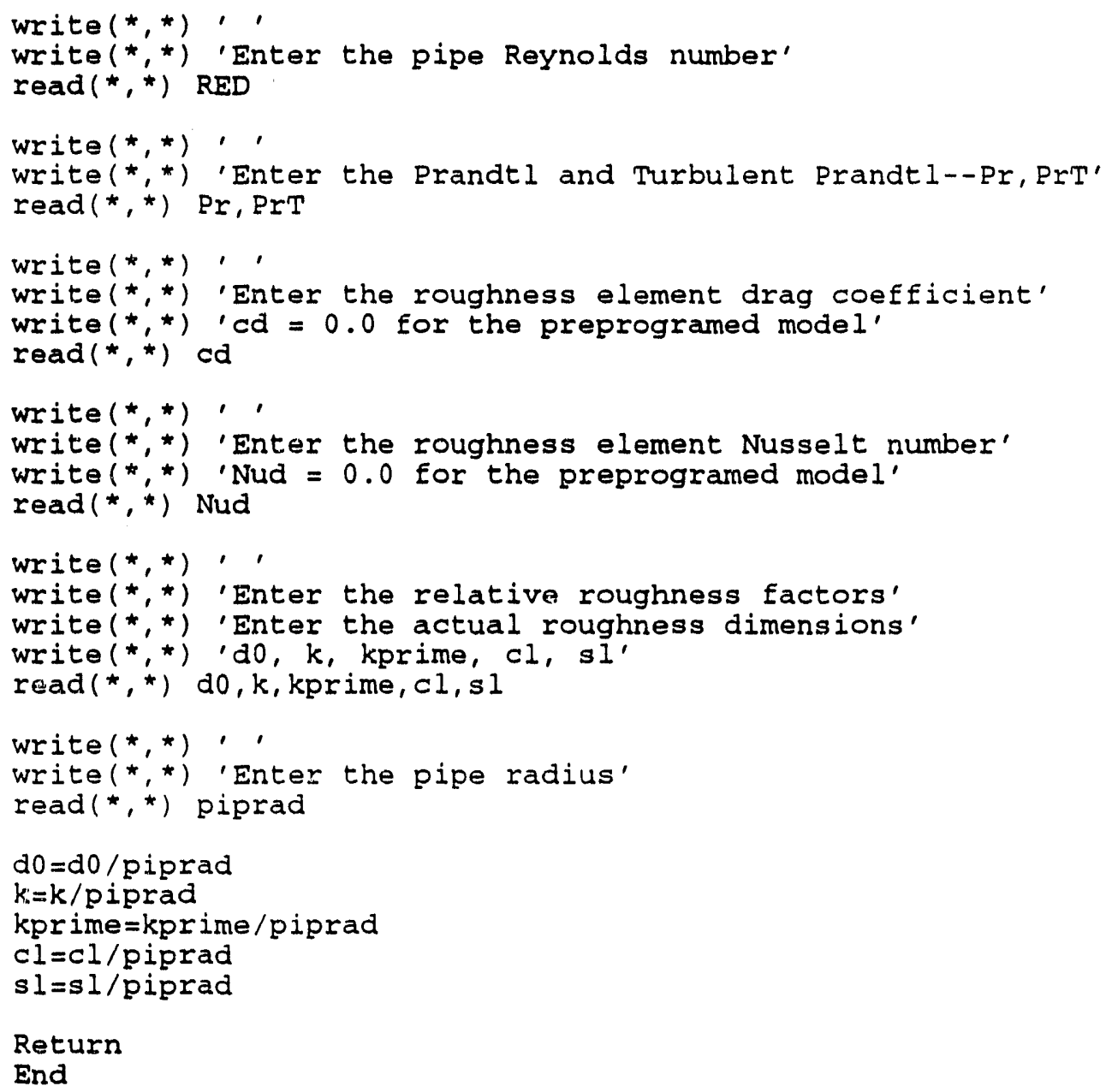

Return

End 
Subroutine GRID(Npts, Y)

Real $y(150)$, r, zeta

Integer Npts, $i$

C This subroutine computes a geometrically expanding grid

$r=1.063$

Npts $=150$

$y(1)=0.0$

zeta $=(r-1) /.(r * *($ Npts -1$)-1$.

Do $100 i=2$, Npts $-1,1$

$Y(i)=y(i-1)+$ zeta

100 zeta $=r *$ zeta

$Y($ Npts $)=1.0$

Return

End

Subroutine ROUGH (Npts, do, k, kprime, y, cl, s1, d, BETA)

Real $y(150), d(150), \operatorname{BETA}(150), d 0, k, k p r i m e, c l, s l$

Real Pi

Integer $i$, Npts

$\mathrm{Pi}=3.1415927$

C This subroutine computes the roughness functions for

C Conical Elements

C Compute local element diameter and Blockage factor

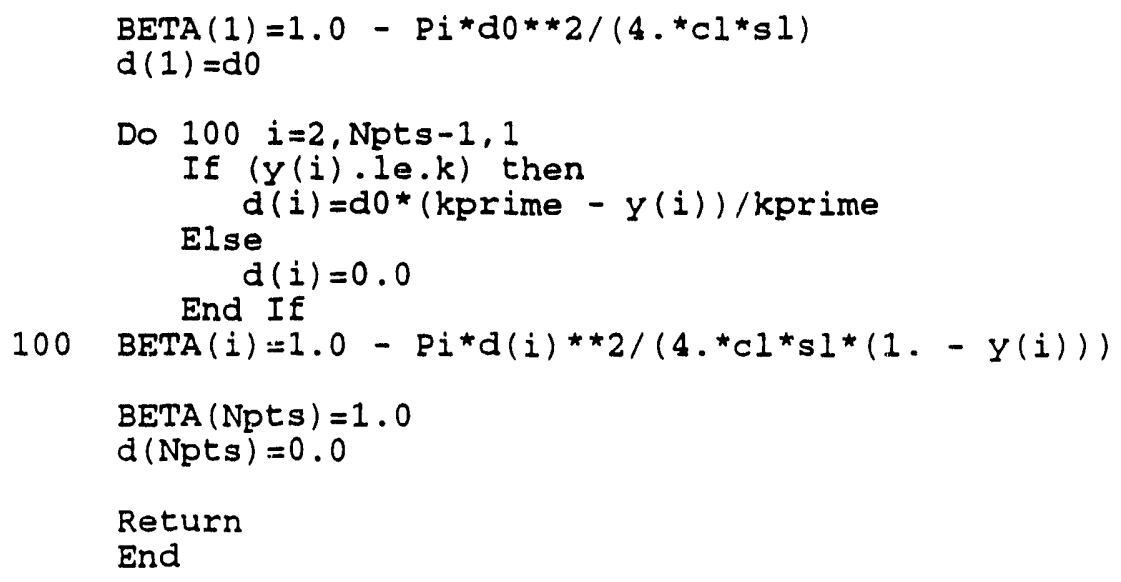


Subroutine FANING (Npts, RED, cd, d, cl, sl,y, BETA, ff, u, aumean, 1 Lstar)

Real RED, cd, cl,sl,y (150), d(150), BETA(150)

Real ff, lowff, lumean, highff, humean, oldff, newff, numean, aumean Real u(150), umean, Lstar (150)

Integer Npts, iter

Logical convrg

C Assume a low value of ff--use smooth wall correlation

If (RED.1t.2000) then

Else lowff $=16$. / RED

lowff $=0.25 /(\log 10(5.74 / R E D * * 0.9)) * * 2 / 4$.

End if

lowf $=$ lowff $/ 2$.

C Compute the velocity profile for lowff

call FLOW (Npts, $y, u, R E D, B E T A$, lowff, cd, $d, c 1, s l$, Lstar)

lumean=umean (Npts, $Y, u, B E T A$ )

C Assume a high value of $\mathrm{ff}$

highf $\mathrm{f}=0.05$

C Compute the velocity profile for highff

call FLOW (Npts, $Y, u, R E D, B E T A$, highff, cd, d, cl, s 1, Lstar)

humean=umean (Npts, $Y, u, B E T A$ )

C Use False Position to iteratively solve for ff

convrg= . FALSE.

oldf $f=0.0$

iter $=1$

C do loop

100 Continue

iter=iter 1

If(iter.gt.100) then

write $(*, *), '$

write $(*, *)$ 'Too many iterations in ff computation' stop

End if

1

newff=lowff $+($ highff - lowff $) *(1.0-$ lumean $)$

call FLOW (Npts, $y, u, R E D, B E T A$, newff, cd, d, cl, sl, Lstar)

numean=umean (Npts, $y, u$, BETA)

If (numean.eq.1.0) then

convrg $=$. TRUE. 


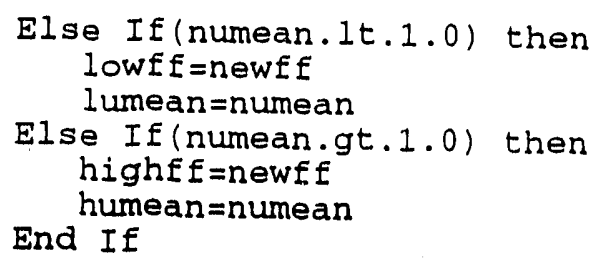

C Check for convergence

If (abs (1.-oldff/newff) .1t.0.01) convrg=.TRUE.

If (.NOT.Convrg) then

oldf $f=$ newf $f$

End If

$C$ End of do loop

f $f=$ newf $f$

aumean =numean

Return

End 
Subroutine NUSLTH (Npts, y, u, Theta, RED, Pr, PrT, BETA, Nud, 1 d, cl, sl, Lstar, Nu, atmean)

Real y(150), u(150), Theta (150), RED, Pr, PrT, BETA (150), Nu, Nud, $1 \quad d(150), c 1, s 1, \operatorname{Lstar}(150)$

Real xtmean, tmean

Integer Npts, $i$

call CONSTH (Npts, $y, u$, Theta, RED, Pr, PrT, BETA, Nud, 1 d, cl,sl, Lstar)

$x t m e a n=\operatorname{tmean}($ Npts $, Y, u, B E T A, T h e t a)$

$\mathrm{Nu}=1.0 / \mathrm{xtmean}$

atmean $=1.0$

Do $100 i=1$, Npts

100 Theta $(i)=$ Nu*Theta $(i)$

Return

End 


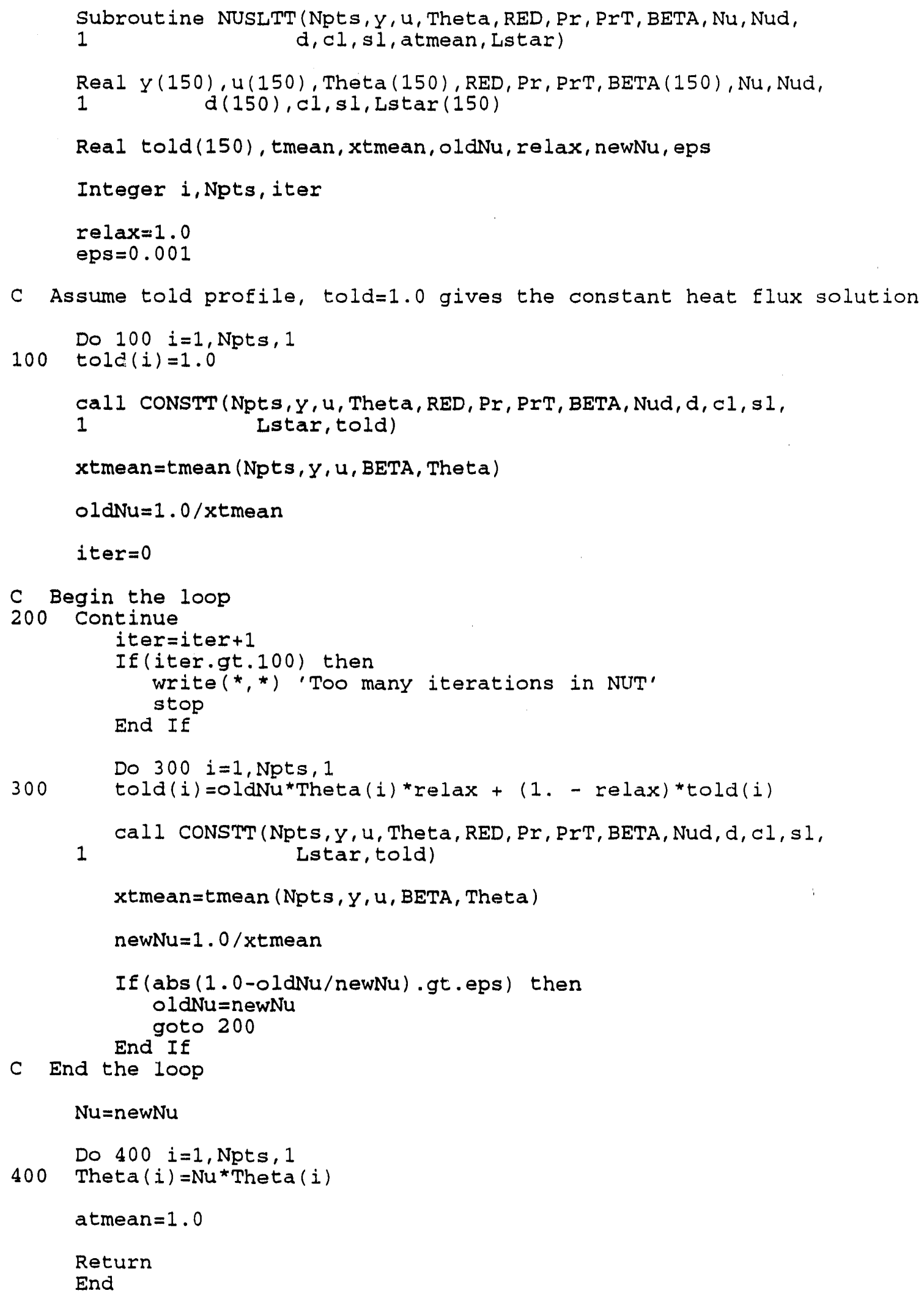




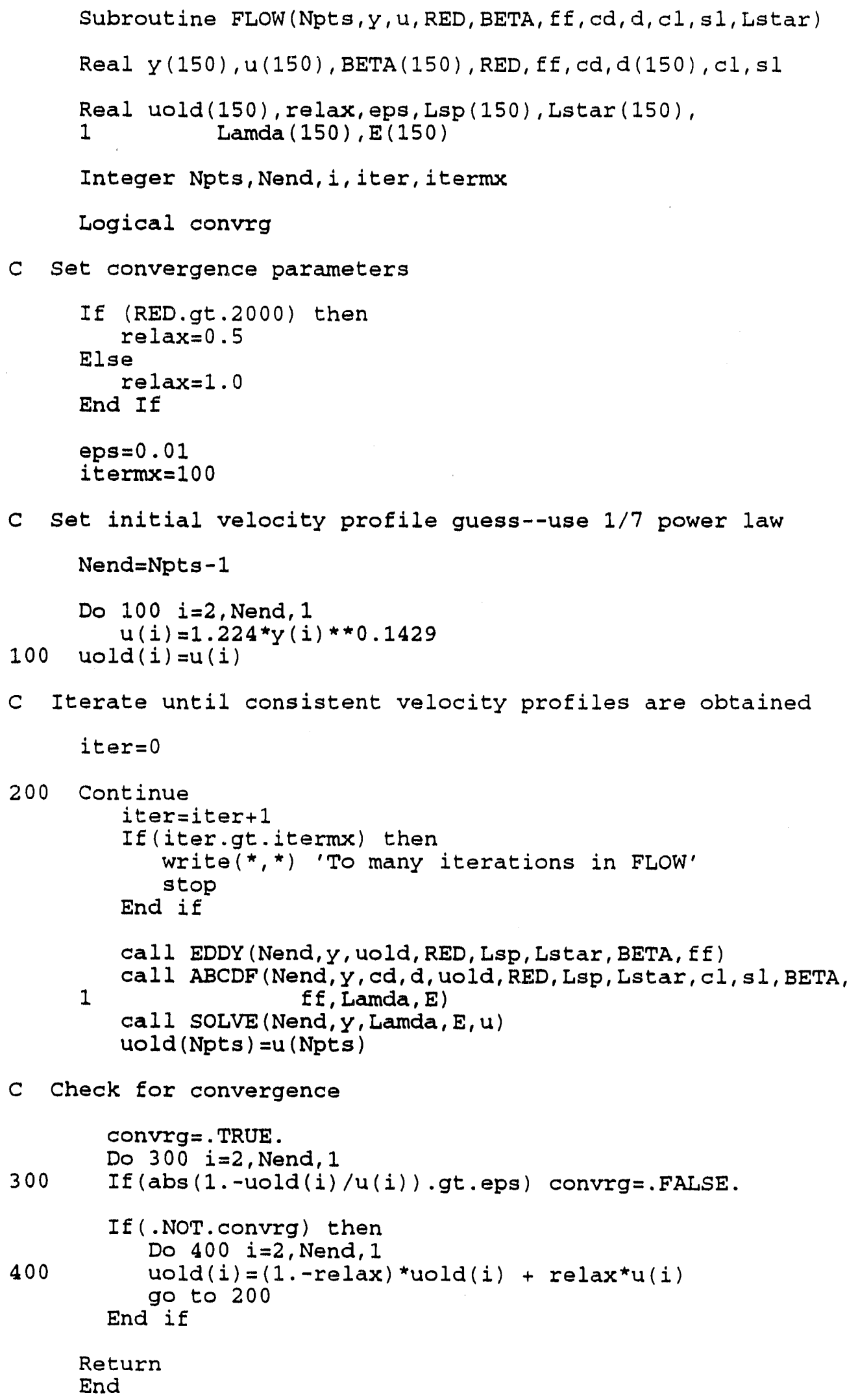


Subroutine CONSTH (Npts, $y, u$, Theta, RED, Pr, PrT, BETA, Nud, 1 d, cl, sl, Lstar)

Real $y(150), u(150)$, Theta (150), BETA (150), d(150), Lstar(150)

Real RED, Pr, PrT, Nud, c1, s1

Real L2star (150), L2sp (150), Lamda2 (150), E2 (150)

Integer Npts, Nend

Nend=Npts - 1

Solve the energy equation for Theta with assumed value of Nu

Theta $(1)=0.0$

cal1 EDDY2 (Nend, $Y$, Lstar, BETA, L2star, L2sp, Pr, PrT)

call ABCDH (Nend, $y$, Nud, $d, u$, Theta, RED, Pr, L2sp, L2star, c1, s1, 1 BETA, Lamda2, E2)

cal1 SOLVE (Nend, $Y$, Lamda2, E2, Theta)

Return

End

Subroutine CONSTT (Npts, $Y, u$, Theta, RED, Pr, PrT, BETA, Nud, 1 d, cl, sl, Lstar, told)

Real $y(150), u(150), \operatorname{Theta}(150), \operatorname{BETA}(150), d(150)$, Lstar (150)

Real told(150)

Real RED, Pr, PrT, Nud, cl, sl

Real L2star(150), L2sp (150), Lamda2 (150), E2 (150)

Integer Npts, Nend

Nend=Npts -1

C Solve the energy equation for Theta with assumed value of Nu

$\operatorname{Theta}(1)=0.0$

cal1 EDDY2 (Nend, Y, Lstar, BETA, L2star, L2sp, Pr, PrT)

call ABCDT (Nend, $y$, Nud, $d, u$, Theta, told, RED, Pr, L2sp, L2star, c1, sl, 1 BETA, Lamaa2, E2)

cal1 SOLVE (Nend, $Y$, Lamda2, E2, Theta)

Return

End 
Real Function umean (Npts, $Y, u, B E T A$ )

Real $Y(150), u(150), \operatorname{BETA}(150)$

Real del, sum

Integer $i$, Npts

C This function computes the mass mean velocity

sum $=0.0$

Do $100 \quad i=2$, Npts, 1

$\operatorname{de} 1=y(i)-y(i-1)$

100 sum $=$ sum + del $*(\operatorname{BETA}(i) *(1 .-y(i)) * u(i)$

$1+\operatorname{BETA}(i-1) *(1 \cdot-y(i-1)) * u(i-1)) / 2$.

umean $=2 \cdot 0^{*}$ sum

Return

End

Real Function tmean (Npts, $Y, u, B E T A$, Theta)

Real $Y(150), u(150), \operatorname{BETA}(150)$, Theta (150)

Real del, sum

Integer $i$, Npts

C This function computes the mass mean temperature

sum $=0.0$

Do $100 \quad i=2$, Npts, 1

$\operatorname{del}=y(i)-y(i-1)$

100 sum $=$ sum $+\operatorname{del} *(B E T A(i) * u(i) *(1 .-y(i)) * \operatorname{Theta}(i)$

$1+\operatorname{BETA}(i-1) * u(i-1) *(1,-y(i-1)) * \operatorname{Theta}(i-1)) / 2$

tmean $=2.0 *$ sum

Return

End 


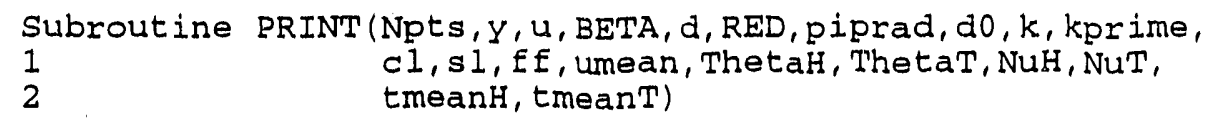

Real $y(150), u(150), \operatorname{BETA}(150), d(150)$, RED, piprad, do, k, kprime

Real cl, sl, ff, umean, ThetaH (150), ThetaT (150), NuH, NuT

Real tmeanH, tmeanT

\section{Integer Npts, $i$ \\ Open (11, FILE=' flow.dat')}

Write $(11,1000)$ RED

1000 Format $('$, 'RED $=$, F7.0, /,' ')

Write $(11,1001)$ piprad

1001 Format (' ', Pipe Radius = ',E14.4,/,' ')

Write $(11,1002)$ do, k, kprime, c1,sl

1002 Format (' ', 'Roughness Parameters', /,' ',

$1 \quad$ 'do $=$ ', E14.4, /,' ',

$2 \quad, k=\prime, E 14,4,1, ', '$

3 'kprime $=$ ', E14.4, /,' ',

$4 \quad{ }^{\prime} \mathrm{Cl}=$, E14.4, /,' ',

$5 \quad$ 'sI $=$, E14.4)

Write $\left(11,{ }^{*}\right)$, '

Write $(11,1003)$ ff, umean

1003 Format (', 'Flow Output', /,' ',

$1 \quad$ 'ff $=$ ', E14.4, /,' ',

2 'umean $=$ ',E14.4)

Write $(11, *), '$

Write $(11,1005) \mathrm{NuH}$, tmeanH

1005 Format(',' Heat Transfer Output--Constant Heat Flux BC',',',', $1 \quad$ 'NuH $=$ ', E14.4, /,' ',

2 'tmeanH $=$ ', E14.4)

Write $(11, *), '$

Write $(11,1006)$ NuT, tmeanT

1006 Format (' ', 'Heat Transfer Output--Constant Temperature BC', /,' ', $1 \quad$ 'NuT $=$ ', E14.4, /,' ',

$2 \quad$ 'tmeanT $=$ ', E14.4)

Write $(11, *)$, ,

Write $(11, *)$ ' $i, y, u$, ThetaH, ThetaT, BETA, d'

Do $100 i=1$, Npts, 1

100 Write $(11,1004)$ i,y (i), u(i), ThetaH(i), ThetaT(i), BETA(i),d(i)

1004 Format (', 'I3, 6E12.3)

Return

End 
Subroutine EDDY (Nend, y, uold, RED, Lsp, Lstar, BETA, ff)

Real y(150), uold(150), Lsp (150), Lstar(150), BETA (150), RED, ff

Real dudy,yplus, mixlen, slstar, corel

Integer $i$, Nend

C This subroutine computes the turbulent eddy viscosity using

$C$ the mixing length model with Van driest damping

C Estimate L*

If (RED.gt.2000) then

$\operatorname{Lstar}(1)=\mathrm{BETA}(1)$

Do $100 i=2$, Nend, 1

$d u d y=(\operatorname{uold}(i)-\operatorname{uold}(i-1)) /(y(i)-y(i-1))$

Yplus =RED*SQRT $(\mathrm{f} f / 2). * \mathrm{Y}(\mathrm{i}) / 2.0$ mixlen $=0.4 * y(i) *(1.0-\operatorname{Exp}(-y p l u s / 26)$.

slstar $=1.0$ + RED*mixlen *mixlen ${ }^{*}$ ABS (dudy) $/ 2.0$ corel $=1.0+0.4{ }^{*} R_{E D} \operatorname{SQRT}(\mathrm{E} f / 2) /$.12 .

If (slstar.gt.corel) slstar=corel

100

$\operatorname{Istar}(i)=\mathrm{BETA}(i){ }^{*} \operatorname{sistar} *(1-y(i))$

Lstar $(\operatorname{Nend}+1)=0.0$

C

Estimate $L^{*}$

Do $200 \quad i=2$, Nend, 1

$\operatorname{Lsp}(i)=(\operatorname{Lstar}(i)-\operatorname{Lstar}(i-1)) /(y(i)-y(i-1))$

Else

Lstar (1) =BETA (1)

Do $300 \quad i=2$, Nend, 1 Lstar $(i)=\operatorname{BETA}(i) *(1 .-Y(i))$

300 $\operatorname{Lsp}(i)=(\operatorname{Lstar}(i)-\operatorname{Lstar}(i-1)) /(y(i)-y(i-1))$

Lstar $($ Nend +1$)=0.0$

End If

Return

End 
Subroutine EDDY2. (Nend, Y, Lstar, BETA, L2star, L2sp, Pr, PrT)

Real y (150), Lstar (150), BElA(150), L2star(150), L2sp (150), Pr, PrT

Integer i, Nend

C This subroutine computes the turbulent eddy conductivity using

$C$ the constant turbulent prandt 1 number model

C Estimate L**

L2star (1) =BETA (1)

Do $100 i=2$, Nend, 1

100 L2star $(i)=\operatorname{Lstar}(i) * \operatorname{Pr} / \operatorname{PrT}+\operatorname{BETA}(i) *(1 .-Y(i)) *(1 .-\operatorname{Pr} / \operatorname{PrT})$

L2star $($ Nend +1$)=0.0$

C Estimate L**'

Do $200 \quad i=2$, Nend, 1

$200 \mathrm{~L} 2 \operatorname{sp}(i)=(L 2 \operatorname{star}(i)-L 2 \operatorname{star}(i-1)) /(y(i)-y(i-1))$

Return

End 
Subroutire ABCDF (Nend, y, cd, d, uold, RED, Lsp, Lstar. $2, s 1, B E T A$, 1 ff, Lamda, E)

Real y(150),d(150), uold(150), Lsp (150), Lstar(150), BETA(150),

1 Lamda (150), E(150), cd, RED, cl, sl, ff

Real db, da, $r, r 2, s 1, s 2, c d 1$, gamma1, gamma2, gamma $3, A, B, C, D D D, z 1$, 1 $r n, z 2, z 3$

Integer i, Nend

C This subroutine computes the coefficients of the finite

$C$ difference equation for the Flow problem.

Do $1000 i=2$, Nend, 1

$C$ set the grid spacing parameters

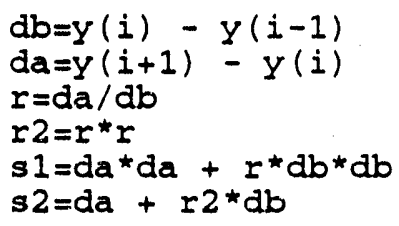

C Compute the element drag coefficient

call DRAG (RED, d (i), uold (i) , cd, cd1)

C Compute the differential equation coefficients

gammal $=L$ sp (i) / Lstar (i)

gamma2 $=-c d 1 * d(i) * R E D * \operatorname{uold}(i) /(4.0 *$ Lstar $(i) * c l * s l)$

gamma $3=B E T A(i) * R E D * f f *(1.0-y(i)) /(2.0 *$ Lstar $(i))$

$C$ set the coefficients of the finite difference equations

$A=2.0 * r / s 1-g a m m a 1 * r 2 / s 2$

$B=-2.0 *(1.0+r) / s 1-g a m m a 1 *(1.0-r 2) / s 2+g a n m a 2$

$\mathrm{C}=2.0 / \mathrm{s} 1+$ gamma1/s 2

$\mathrm{DDD}=-$ gamma 3

C Set the coefficients of the cononical matrix

If (i.eq.2) then

Lamda $(2)=B / C$

$E(2)=(D D D-A *$ Uold $(1)) / C$

Else if (i.eq.Nend) then

$\mathbf{z} 1=0.0$

$r n=2.0 * r+1.0$

$z 2=-r 2 / r n$

$z 3=(1.0+r) *(1.0+r) / r n$

Lamda (Nend) $=B+C^{\star} z 3-\left(A+C^{\star} z 2\right) /$ Lamda (Nend -1$)$

Else

$E($ Nend $)=D D D-C * z 1-\left(A+C^{\star} z 2\right) * E($ Nend-1)/Lamda (Nend-1)

$\mathrm{rn}=\mathrm{C}^{\star} \operatorname{Lamda}(i-1)$

Lamda $(i)=B / C-A / r n$

End if

$E(i)=D D D / C-A * E(i-1) / I n$

1000 Continuet

Return

End 
Subrout ine ABCDH (Nend, $y$, Nud, $d, u$, Theta, RED, Pr, L2sp, L2star, cl, sl, 1 BETA, Lamda2, E2)

Real y(150), d(150), u(150), Theta (150), L2sp (150), L2star(150), 1 $\operatorname{BETA}(150)$, Lamda2 (150), E2 (150), Nud, RED, Pr, cl, sl

Real db, da, r, r2 , s1, s2, Nud1, gamma1, gamma2, gamma 3, A, B, C, DDD, z1, $1 \quad \mathrm{rn}, \mathrm{z2}, \mathrm{z} 3$

Integer $i$, Nend

$C$ This subroutine computes the coefficients of the finite

$C$ difference equation for the Heat Transfer problem.

Do $1000 \quad i=2$, Nend, 1

C Set the grid spacing parameters

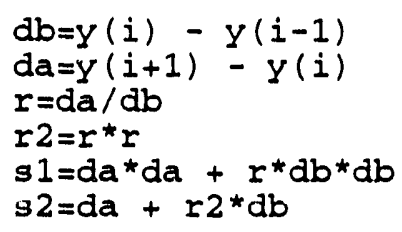

c Compute the element Nusselt number

Call HEAT (RED, Pr, d (i), u(i), Nud, Nud1)

C Compute the differential equation coefficients

gamma $1=$ L2sp $(i) /$ L2star $(i)$

gamma2 $=-\mathrm{Nud1}$ *3.1415927/(cl*s $\left.1{ }^{*} \mathrm{~L} 2 \mathrm{star}(i)\right)$

gamma $3=3 E T A(i) * u(i) *(1.0-y(i)) /$ L2star $(i)$

$C$ Set the coefficierts of the finite difference equations

$A=2.0 * r / s 1$ - gamma $1 * r 2 / s 2$

$\mathrm{B}=-2.0 *(1.0+r) / \mathrm{s} 1$ - gamma $1 *(1.0-\mathrm{r} 2) / \mathrm{s} 2+$ gamma 2

$C=2.0 / s 1+g a m m a 1 / s 2$

$\mathrm{DDD}=-$ gamma 3

$C$ Set the coefficients of the cononical matrix

If (i.eq.2) then

Lamda2 $(2)=B / C$

$E 2(2)=(D D D-A *$ Theta (1)) $/ C$

Else if (i.eq.Nend) then

$z 1=0.0$

$r n=2.0 * r+1.0$

$\mathrm{z} 2=-\mathrm{r} 2 / \mathrm{rn}$

$z 3=(1.0+r) *(1.0+r) / r n$

Lamda2 (Nend) $=B+C^{\star} z 3-\left(A+C^{\star} z 2\right) /$ Lamda2 (Nend -1 )

Else

$E 2($ Nend $)=D D D-C^{\star} z 1-(A+C * z 2) * E 2($ Nend -1$) /$ Lamda2 $($ Nend -1$)$

$r n=C *$ Lamda2 $(i-1)$

Lamda2 $(i)=B / C-A / r n$

End if

$E 2(i)=D D D / C-A * E 2(i-1) / r n$

1000 Continue

Return

ind 
Subroutine ABCDT(Nend, $y$, Nud, $d, u$, Theta, told, RED, Pr, L2sp, L2star, 1 c1, s1, BETA, Lamda2, E2)

Real $y(150), d(150), u(150)$, Theta (150), L2sp(150), L2star(150), 1 told (150), BETA (150), Lamda2 (150), E2 (150), Nud, RED, Pr, $2 \quad \mathrm{cl}, \mathrm{sl}$

Real $d b, d a, r, r 2, s 1, s 2$, Nud1, gammal, gamma2, gamma $, A, B, C, D D D, z 1$, 1 $\mathrm{rn}, \mathrm{z2}, \mathrm{z3}$

Integer $i$, Nend

C This subroutine computes the coefficients of the finite

C difference equation for the Heat Transfer problem.

Do $1000 \quad i=2$, Nend, 1

C Set the grid spacing parameters

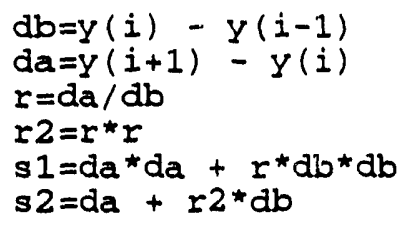

C Compute the element. Nusselt number

call HEAT (RED, Pr, d (i), u(i), Nud, Nudl)

C Compute the differential equation coefficients gamma $1=\mathrm{L} 2 \mathrm{sp}(\mathrm{i}) / \mathrm{L} 2 \mathrm{star}$ (i) gamma2 $=-\operatorname{Nud1} * 3.1415927 /(c 1 * s 1 * L 2 s \operatorname{sar}(i))$ gamma $3=B E T A(i) * u(i) *(1.0-Y(i)) * \operatorname{told}(i) / L 2 \operatorname{star}(i)$

C Set the coefficients of the finite difference equations

$A=2.0 * r / s 1$ - gamma $1 * r 2 / s 2$

$B=-2.0 *(1.0+r) / s 1-$ gamma $1 *(1.0-r 2) / s 2+$ gamma 2

$\mathrm{C}=2.0 / \mathrm{s} 1+$ gamma1/s2

$\mathrm{DDD}=-$ gamma 3

C Set the coefficients of the cononical matrix

If (i.eq.2) then Lamda $2(2)=B / C$ $E 2(2)=(D D D-A * T h e t a(1)) / C$

Else if(i.eq.Nend) then

$\mathrm{zl}=0.0$

$r n=2.0 * r+1.0$

$\mathrm{z} 2=-\mathrm{r} 2 / \mathrm{rn}$

$z 3=(1.0+r) *(1.0+r) / r n$

Lamda2 (Nend) $=B+C * z 3-\left(A+C^{*} z 2\right) /$ Lamda2 (Nend-1)

Else E2 (Nend) $=D D D-C^{\star} z 1-\left(A+C^{\star} z 2\right) * E 2($ Nend-1)/Lamda2 $($ Nerd -1$)$

$r n=C *$ Lamda2 $(i-1)$

Lumda2 $(i)=B / C-A /$ rn

End $i f$

$E 2(i)=D D D / C-A * E 2(i-1) / r n$

1000 continue

Return

End 
Subrout ine SOLVE (Nend, $Y$, Lamda, $E, w$ )

Real y (150), Lamda (150), E(150),w(150)

Real da, db, $r, r 2, b 1, b 2$

Integer $i$, Nend

C This subroutine solves the cononical equations by back

C substitution

C Solve for the next to last value

$\mathbf{w}($ Nend $)=\mathbf{E}($ Nend $) /$ Lamda $($ Nend $)$

C Solve for the other values by back substitution

Do $100 \quad i=$ Nend $-1,2,-1$

$100 w(i)=(E(i)-w(i+1)) /$ Lamda $(i)$

C Use 3-point approximation for derivative to calculate the

C pipe center line value from symmetry condition

C $\quad d w / d y=0$ at $y=1$

da $=y($ Nend +1$)-y($ Nend $)$

$\mathrm{db}=\mathrm{y}$ (Nend) $-Y($ Nend -1$)$

$r=d a / d b$

$r 2=r * r$

$b 1=\left(r 2+2 \cdot{ }^{*} r+1\right) /\left(2 \cdot{ }^{\star} r+1\right)$

$\mathrm{b} 2=-\mathrm{r} 2 /\left(2 \cdot{ }^{\star} r+1\right)$

$w($ Nend +1$)=b 1 * w($ Nend $)+b 2 * w($ Nend -1$)$

Return

End 


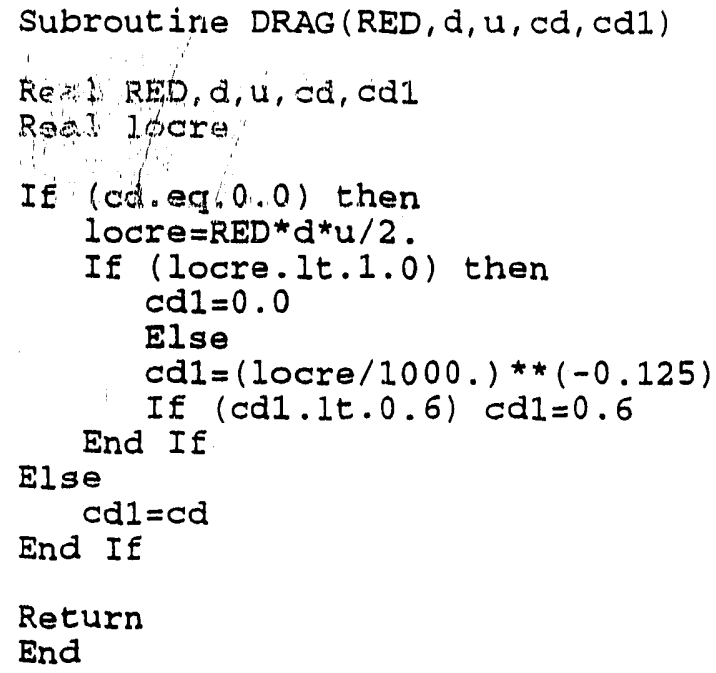


$\therefore$
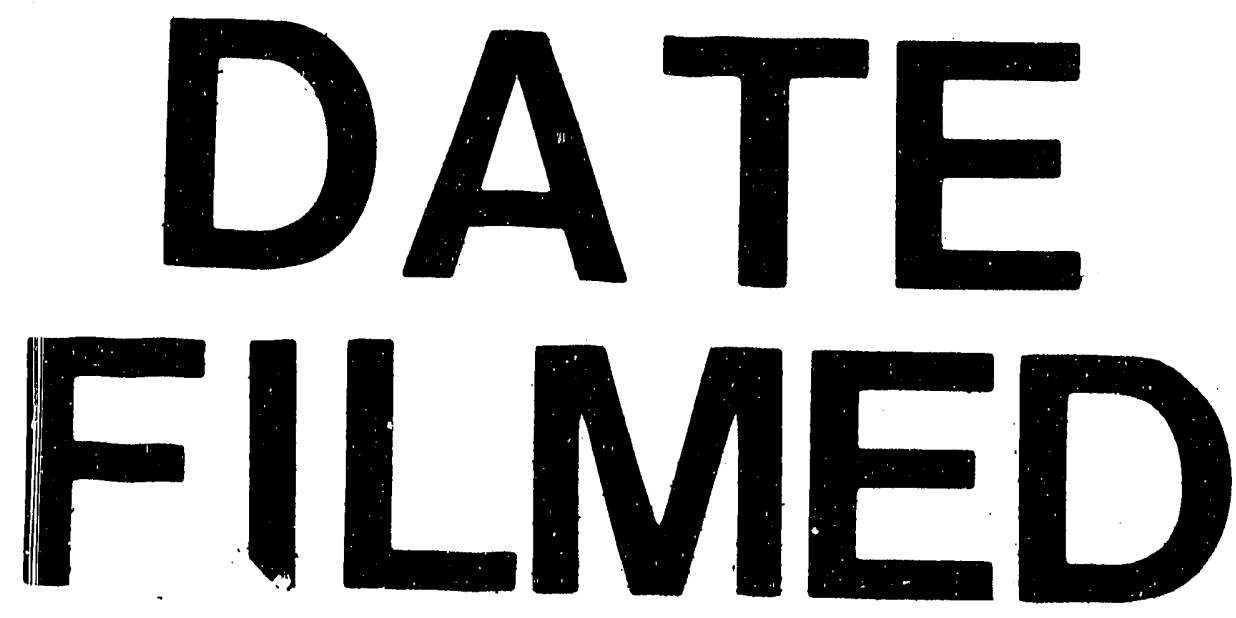

$8 / 12 / 92$ 
